\title{
$\begin{array}{ll}\text { Research Square } & \text { Preprints are preliminary reports that have not undergone peer review. } \\ \text { They should not be considered conclusive, used to inform clinical practice, }\end{array}$ or referenced by the media as validated information. \\ Air Quality And Health Benefits of Increasing Carbon Mitigation Tech-Innovation In China
}

\section{Shunlin Jin}

Jiangsu University https://orcid.org/0000-0002-0510-4699

Weidong Wang ( $\nabla$ wangwd@ujs.edu.cn )

Jiangsu University

\section{Dragana Ostic}

Jiangsu University

\section{Caijing Zhang}

Nanjing Agricultural University

$\mathrm{Na} \mathrm{Lu}$

Jiangsu University

Dong Wang

Jiangsu University

Wenli Ni

Jiangsu University

\section{Research Article}

Keywords: Carbon mitigation tech-innovation, Haze pollution, Health benefits, Sustainable development, Mediating effect

Posted Date: September 13th, 2021

DOI: https://doi.org/10.21203/rs.3.rs-800136/v1

License: (c) (i) This work is licensed under a Creative Commons Attribution 4.0 International License.

Read Full License 


\title{
Air quality and health benefits of increasing carbon mitigation tech-innovation in China
}

\author{
Shunlin Jin ${ }^{1}$,Weidong Wang ${ }^{1}{ }_{-}^{-}$, Dragana Ostic ${ }^{1}$,Caijing Zhang ${ }^{2}, \mathrm{Na} \mathrm{Lu}^{1}$, Dong Wang ${ }^{1}$,Wenli $\mathrm{Ni}^{1}$
}

\section{ABSTRACT:}

Most studies on the short-term local benefits of carbon mitigation technologies on air quality improvement and health focus on specific technologies such as biofuels or Carbon sequestration technologies, while ignoring the overall role of the growing scale of low-carbon technologies, and the relevant empirical studies are particularly lacking. Based on STIRPAT model and EKC hypothesis, this paper takes 30 provinces of China from 2004 to 2016 as research samples, measures the carbon mitigation tech-innovation(CMTI) with Y02 low carbon patent applications, and constructs a econometric model to empirically analyze the effect of carbon mitigation tech-innovation in response to climate change on the inhibition of haze pollution. It draws on relevant studies to quantify air quality and health benefits of carbon mitigation tech-innovation. Research shows that a $1 \%$ increase in the number of low-carbon patent applications can reduce haze pollution by $0.066 \%$. According to this estimate, to 2029, China's carbon mitigation tech-innovation could reduce $P M_{2.5}$ concentration to $15 \mu \mathrm{g} / \mathrm{m}^{3}$ preventing 5.597million premature deaths. The research further found that carbon mitigation tech-innovation can also indirectly inhibit haze pollution by triggering more systematic economic structure changes such as energy and industrial structure. Additionally, the study found that the role of grey

\footnotetext{
${ }^{1}$ School of Finance and economics, Jiangsu University, Zhenjiang, China. ${ }^{2}$ School of public administration, Nanjing Agricultural University, China. E email:wangwd@ujs.edu.cn
} 
tech-innovation(GT) related to improving the efficiency of fossil energy is stronger than that of clean technology $(\mathrm{CT})$ related to the use of renewable energy. This suggests that for a large economy such as China, where coal is still the dominant source of energy consumption, the short-term local benefits of improving air quality and health through the use of grey tech-innovation to improve energy and industrial structure are still important to balance the cost of carbon mitigation.

Keywords: Carbon mitigation tech-innovation; Haze pollution; Health benefits; Sustainable development; Mediating effect

\section{Introduction}

Since the reform and opening up, China's economic development has made remarkable achievements, but the air pollution caused by rapid industrialization and urbanization is one of the biggest environmental challenges facing China at present (Lin et al.,2010; Guan et al.,2012; Lyu et al.,2016; Zeng et al.,2019; Zhao et al., 2021). In fact, as early as 2013, the Chinese government began to implement the Air Pollution Prevention and Control Action Plan. And In June 2018, the State Council issued the Three-Year Action Plan to Win the Blue Sky Defense War. Although the Chinese government has taken a number of measures to curb the country's worsening air pollution, it doesn't seem to be having the desired effect. In 2019, 180 of the country's 337 cities at or above the prefecture level exceeded the standard, accounting for 53.4 percent. 337 cities had 1,666 days of heavy pollution. If the impact of sand and dust is not deducted, the proportion of cities exceeding the standard will reach 
57.3\% (Ministry of Ecology and Environment,2020). Severe air pollution leads to widespread smog problems in many Chinese cities (Feng and Robert,2012; Apet et al.,2015; Yin et al.,2019; Yin and Wang,2017; Yin and Zhang,2020), and one of the main causes of haze problem is the increase in the concentration of particulate matter $\left(P M_{2.5}\right)$ in the atmosphere (Hsu et al.,2017; Liao et al., 2017). Relevant data show that among the major air pollutants, the fine particulate matter $(2.5 \mu \mathrm{m}$ or smaller in diameter, $P M_{2.5}$ ) has the greatest effect (Yu et al.,2016; Xie et al.,2019). In 2019, the number of days with $P M_{2.5}$ as the primary pollutant in China accounted for 78.8 percent of the days with severe pollution or above, the average concentration was 37 $\mu \mathrm{g} / \mathrm{m}^{3}$. (Ministry of Ecology and Environment,2020). Continuous $P M_{2.5}$ pollution not only leads to the large-scale spread of haze in China, but also causes a sharp decline in air quality and dual loss of health benefits and economic benefits (Guan et al.,2016; Abajobir et al.,2016; Li et al.,2018; Liu et al.,2018; Zhao et al.,2018; Guan et al.,2019; Zhang et al., 2019). It is estimated that by 2060 , the country with the greatest economic losses due to air pollution will probably be China (Lanzi et al.,2018).

Related to smog pollution, climate change is one of the biggest threats facing all living things in the 21 st century. Over the years, a large number of emissions of greenhouse gases (mainly $\mathrm{CO}_{2}$ ) lead to global warming, climate change is very outstanding, and long-term climate change will not only bring serious threat to human existence, may also lead to the collapse of the earth's ecological system, even human health problems brought by the response to climate change, Governments need to invest a large amount of capital cost every year (Landrigan et al.,2018; Tong et 
al.,2019; Coelho et al.,2020; Liu et al.,2020a; Wright et al.,2021). In response to this threat, China signed a commitment at the Paris Agreement in 2015 to reduce energy intensity by $60-65 \%$ from 2005 levels by 2030 , and to peak carbon emissions around 2030 or even earlier. In 2020, China has further announced new nationally determined contribution targets such as carbon peak and carbon neutrality, which are included in the 14th Five-Year Plan (2021-2025). It can be seen that carbon emission reduction has been the task of China for a long time now.

Effective carbon emission reduction is the only way to deal with global climate change, and it has an important synergistic effect on air quality and human health (Xie et al.,2018; Cao et al.,2019; Scovronick et al.,2019; Sharifi et al.,2020), and the value generated by this effect is higher in developing countries (Nemet et al.,2010a). A major obstacle to carbon reduction is the difficulty of reconciling the global, long-term benefits of climate change with the short-term, local costs. However, relevant studies suggest that most air pollutants (mainly $P M_{2.5}$ ) share a common source with greenhouse gases (mainly $\mathrm{CO}_{2}$ ) (West et al.,2004; West et al.,2013a), carbon emission reduction actions will reduce other emissions of air pollution, such as $\mathrm{CO}_{2}, \mathrm{SO}_{2}$ and $\mathrm{NO}_{x}$, which can bring short-term and partial health benefits and relieve the short-term cost pressure of emission reduction actions (Zhang et al.,2017; Cai et al.,2018a; Wang et al., 2020 a; Liu et al., 2020b). However, most of these studies have focused on assessing the air quality and health benefits of carbon reduction policies such as carbon trading, carbon pricing, and carbon taxes (Thompson T M et al.,2014a; Shindell D et al.,2018; Scovronick et al.,2019; Chang et al., 2020a; Yang et al.,2021a), 
or focus on assessing the benefits of individual technologies such as biofuels and carbon sequestration (CCS) to address climate change (Ou et al.,2018a; Wang et al.,2020b), but less consideration is given to the overall short-term air quality and health benefits of the increasingly large scale carbon mitigation tech-innovation, and the relevant empirical and impact mechanism studies are particularly lacking. Based on this, this paper takes China as the background to analyze three issues: How will the increasingly active technological innovation of carbon emission reduction triggered by long-term global climate change affect the short-term and local benefits of air quality? What is the role of important relevant factors such as energy structure and industrial structure in the influencing process? Is there heterogeneity in the impact of different types of low-carbon technology innovation activities, such as clean technology and grey technology innovation?

The innovation and improvement of the research include:

(1) Extend the research on air quality benefits of current climate change technologies from scenario simulation of individual negative emission technologies to empirical research of low-carbon technologies as a whole. For the first time, the empirical method based on historical data and the STIRPAT model and the classical EKC hypothesis will be integrated to build an econometric model to study the common benefits of carbon emission reduction measures. Different from the previous simulation methods, which are mainly based on scenario setting, to analyze the air quality benefits of specific negative emission technologies (Ou et al.,2018b; Wang et al., 2020 b). 
(2) The hypothesis of "externality" of carbon mitigation tech-innovation will be

112

further studied. Current studies generally assume that carbon emission reduction technological innovation is constrained by "double externalities", that is, it is difficult to recover both economic and environmental benefits of innovation, resulting in insufficient incentives (Horbach et al.,2012; Cunico et al., 2017). However, the benefits of air quality and health are often neglected in the calculation of the benefits of carbon mitigation tech-innovation, so the benefits of carbon mitigation tech-innovation are underestimated. The calculation of such benefits has a direct impact on the decision-making of climate change action. If the benefits are large, it is more worthwhile to use environmental policy and technological means to deal with climate change action.

(3) Industrial structure and energy structure are included in the study to more accurately and completely reveal the impact mechanism of carbon mitigation tech-innovation on reducing haze pollution.

(4) The carbon mitigation tech-innovation is divided into clean technology and grey technology, and the possible heterogeneity of different types of low-carbon technologies on the prevention and control effects of haze pollution is studied.

\section{Literature review and theoretical hypotheses}

\subsection{Carbon mitigation tech-innovation and Haze Pollution}

Due to the obvious homology between greenhouse gases and haze, it has created great potential for common control (Dong et al.,2015a). Research on co-control or 
co-benefit focuses on the simultaneous reduction of local emissions of air pollutants through measures to reduce greenhouse gas emissions, or measures to reduce local air pollutants at the same time. (Rypdal K et al.,2007; Tollefsen P et al.,2009; Yeora C et al.,2010; Mao et al., 2012; Kanada et al.,2013) As for the former, situational simulation is often used in studies. For example, Nemet et al.(2010b) found that the health benefits of GHG emission reduction are equivalent to the costs of GHG emission reduction. West et al.(2013b) estimate that economic and energy system transformation under climate mitigation scenarios will reduce air pollutant emissions and prevent 1.3 million premature deaths worldwide in 2050 due to $P M_{2.5}$ and ozone exposure. Shindell et al.(2016) found that according to the global target of controlling temperature rise within $2^{\circ} \mathrm{C}$ by 2050 , the short-term benefits of carbon dioxide reduction in the United States may exceed the policy costs. Recently, research on specific emission reduction policies has been strengthened. For example, studies show that carbon dioxide emission standards for the power generation industry in the United States will affect the fuels and technologies used for power generation, as well as environmental air quality and public health (Driscoll C et al.,2015). Thompson et al.(2014b) studied the role of carbon cap-and-trade system and clean energy standards in the United States in 2030 and found that the improved health benefits brought by improved air quality could offset $26 \%-1050 \%$ of the cost of carbon reduction policies. Garcia-Menendez et al.(2015) found that a global carbon tax could significantly reduce emissions of air pollutants, and that the benefits of such a policy would increase over time. Trail et al.(2015) found that a relatively aggressive carbon tax may 
lead to a significant improvement in $P M_{2.5}$ air quality in the United States. The results of Ou et al.(2016) suggest that greenhouse gas emission reduction measures may also have adverse effects.

In recent years, the coordinated governance of climate change and haze has attracted great attention of the Chinese government. This kind of research with China as its object has emerged in recent years (Yang et al.,2018). First, research based on region, industry and technology. The study points out that the shared health benefits of reducing greenhouse gas emissions are most pronounced in East Asia, with two-thirds of the global shared benefits expected to occur in China by 2030 (Cai et al.,2018b). Yang et al.(2013a) found that deployment of distributed photovoltaic systems in eastern rather than western China and interprovincial transmission would maximize the health benefits associated with carbon dioxide emission reduction and air quality by 2030. Dong et al.(2015b) found that provinces with high energy consumption or relatively intensive coal or industry in China gained greater common benefits. Yang et al.(2013b) calculated the synergistic benefits of energy-saving technologies in China's cement industry. Cai et al.(2018c) estimated that by $2030,18 \%-62 \%$ of the implementation cost of renewable power generation in the power generation industry could be covered by health benefits, which would significantly increase to 3-9 times the cost by 2050. Second, research based on climate policy. He et al.(2010) quantified the impact of China's energy policy on air pollution, focusing on the formation of fine particulate matter $P M_{2.5}$. Nielsen and $\mathrm{Ho}(2013)$ show that a nationwide carbon dioxide tax during the Eleventh Five-Year Plan period is expected to improve air 
quality at a low cost. Chang et al.(2020b) found that under a national carbon emission trading system, air quality and health benefits would be significantly improved. In China's committed 2030 carbon peak policy scenario, the health benefits of improved air quality will partially or fully offset the policy costs (Li et al.,2018). Yang et al.(2021b) assess the benefits of carbon and pollution control policies for air quality and human health through a comprehensive framework that combines an energy economic model, an air quality model and a concentration-response model.

Increasingly serious haze pollution is the most significant external manifestation of air quality deterioration. How to effectively improve haze pollution is the key to achieve common benefits of air quality. According to the above review, a large number of literatures still focus on the policy aspect, and only some literatures mention technological innovation, which is limited to specific negative emission technologies (Ou et al.,2018c). There is very little research on the effect of carbon emission reduction technologies on haze control from the overall perspective of technology. The use of environmental policies often means high economic and social costs, which are short-term and difficult to fundamentally address, such as closing down high-polluting enterprises. Compared with policies, the economic and social costs of technological innovation should be relatively low and sustainable in the long term, which is conducive to the fundamental control of haze pollution. In recent years, the number of low-carbon patent applications in the world and China has increased rapidly. As can be seen from Fig.1, from 2004 to 2016, the total number of low-carbon patent applications (including clean and gray) in China jumped from 
7,000 to about 150,000 , making China the major low-carbon patent application country in the world. Among them, the number of clean and gray patent applications also experienced rapid growth, which should be conducive to haze control. The effect of inhibiting haze. Thus, the following hypothesis is proposed:

H1. carbon mitigation tech-innovation to curb haze pollution.

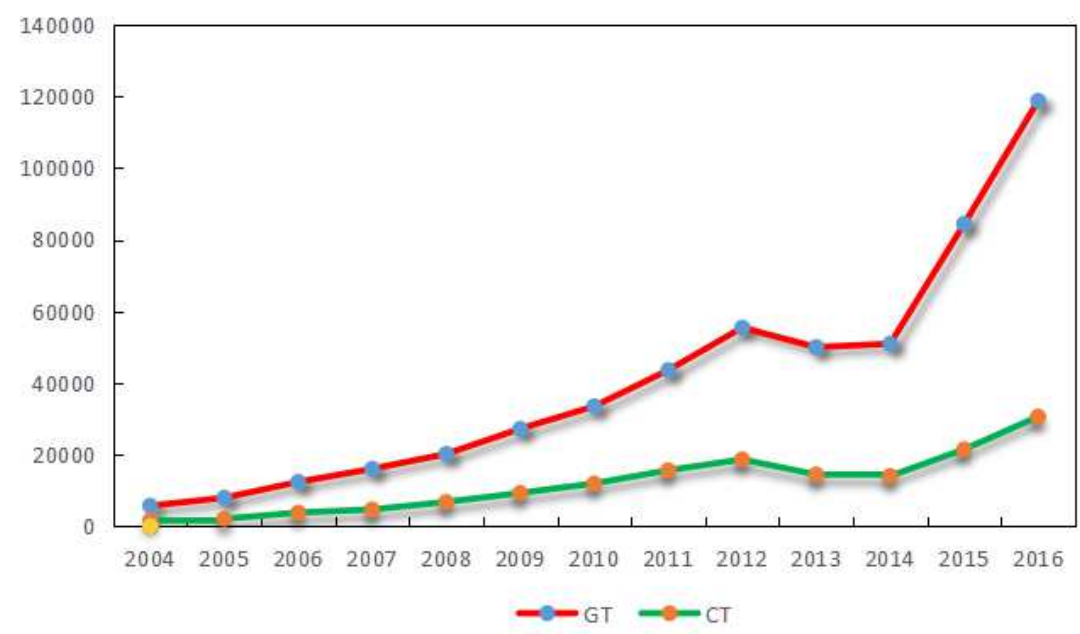

Fig. 1. Number of clean and gray patent applications in China from 2004 to 2016

\section{2.carbon mitigation tech-innovation, energy structure and Haze Pollution}

Technological innovation and energy structure optimization are both important means to achieve sustainable development goals. Energy structure generally refers to the composition and proportion of all kinds of energy in the total amount of energy. For example, the advantages and disadvantages of energy structure are judged by the proportion of coal, oil and other fossil energy consumption. The optimization of energy structure may come from both policy pressure and technological change. Lin and Chen.(2019) found that wind power technology innovation is the key to achieve energy structure transformation and sustainable economic development. For the metal industry, technological progress can also improve energy efficiency by changing 
factor shares (Lin and Chen.2020). Wurlod et al.(2018) point out that green technology innovation can help reduce energy intensity and achieve the core objectives of climate policy. Studies by other scholars have found that energy efficiency cannot be effectively improved only by adjusting industrial structure. Only by relying on more advanced technologies can the problems of high emissions and high energy consumption in industrial production be effectively solved, so as to improve energy efficiency and bring about predictable adjustment of energy structure (Shao et al., 2019; Wang and Wang, 2020). In fact, technological innovation is indeed the key to the transformation of the energy structure. A large number of technological innovation is conducive to those industries that rely on traditional energy (such as steel, electricity, construction industry, etc.) to gradually transition to clean energy, such as the use of renewable energy such as wind and solar energy. At the same time, some gray technology innovations will significantly improve the energy utilization efficiency of enterprises and reduce energy intensity, which plays an important role in promoting the improvement of energy structure. Therefore, carbon mitigation tech-innovation should promote the transformation of energy structure while reducing haze. Thus, the following hypothesis is proposed:

H2a. Carbon mitigation tech-innovation will promote the optimization of energy structure.

Studies show that excessive fossil energy consumption and high fossil energy intensity are both important causes of haze pollution (Li et al.,2017; Jing et al.,2018), the improvement of both plays an important role in the improvement of air quality 
(Dong et al.,2019). In recent years, China's rapid industrialization and urbanization have led to a large amount of fossil energy consumption, which makes it difficult to improve the imbalance of energy structure and inevitably brings a large amount of polluting gas emissions, leading to frequent and large-scale occurrence of haze pollution (Liu et al.,2016a; Yao et al., 2018; Zhou et al., 2018). Accordingly, the following hypotheses are proposed:

H2b. Optimization of energy structure will curb haze pollution.

According to H2a and $\mathbf{H 2 b}$, it can be inferred that carbon emission reduction technological innovation may also indirectly affect haze pollution through energy structure. Thus, the following hypothesis is proposed:

H2c. Energy structure plays an intermediary role in the impact of carbon emission reduction technological innovation on haze pollution.

\subsection{Carbon mitigation tech-innovation and Industrial structure and Haze}

\section{Pollution}

Technological innovation is also the key to the upgrading of industrial structure. As early as 1989, Arthur.(1989) had found that technological innovation was conducive to the upgrading of industrial structure. With the increasing appeal of environmental protection products and cleaner production, enterprises adopt low-carbon technology innovation or low-carbon technology to adapt to social development and meet social needs, so as to obtain comparative competitive advantages and improve enterprise competitiveness and performance ( $\mathrm{Li}$ et al.,2019; Li et al., 2021). Researchers clearly point out that widespread technological 
innovation in the industry can not only improve the environment, but also optimize the efficiency of capital allocation (Zhao et al.,2021). Funds in the market will flow to

261 industries with development potential, such as new energy vehicles, photovoltaic 262 power generation and other environmental protection industries. In the long run, the number of high-pollution enterprises in the secondary industry will be reduced, the overall improvement of the industrial system will be brought about, and the transformation of the overall structure will be promoted (Zhao and Wang.2020). However, part of the current research on industrial structure upgrading focuses on the effect of government policies on industrial structure upgrading (Zheng et al.,2021a; Du et al.,2021). However, such policies often ignore the possibility of industrial migration. In fact, due to the "race to the bottom" and the "Pollution Haven Hypothesis" among local governments, the migration of high-carbon industries in

271 China has become common. This leads to the failure of local industrial policies and environmental regulations to some extent (Shen et al.,2019). In contrast, the use of 273 technological innovation to promote industrial upgrading may have more obvious advantages. Thus, the following hypothesis is proposed: upgrading of industrial structure. most critical factor for solving environmental problems (Oosterhaven and

279 Broersma.2007). Li et al.(2017) believe that industrial structure upgrading can help improve the efficiency of resource utilization and thus improve environmental 
problems, and can also effectively alleviate the contradiction between economic development and energy conservation and emission reduction. Chen et al.(2019) also believe that in the long term, the upgrading of industrial structure is conducive to the improvement of air pollution. In recent years, with the acceleration of urbanization and industrialization in China, the high-carbon industry is still the pillar industry in China (Zheng et al.,2021b). And, in the industrial structure of China, the "three high" and "three wastes" (waste water, waste gas, And waste residue), and these problems directly lead to the decline of haze pollution and air quality(Zhu et al.,2019). Accordingly, the following hypothesis is proposed:

H3b. The upgrading of industrial structure will curb haze pollution.

According to $\mathbf{H 3 a}$ and $\mathbf{H 3 b}$, carbon mitigation tech-innovation may inhibit haze pollution by promoting industrial structure upgrading. Accordingly, the following hypothesis is proposed:

H3c. Industrial structure plays an intermediary role in the impact of carbon mitigation tech-innovation on haze pollution.

In summary, the methodological framework of the above five theoretical hypotheses in this thesis is illustrated in Fig.2. 


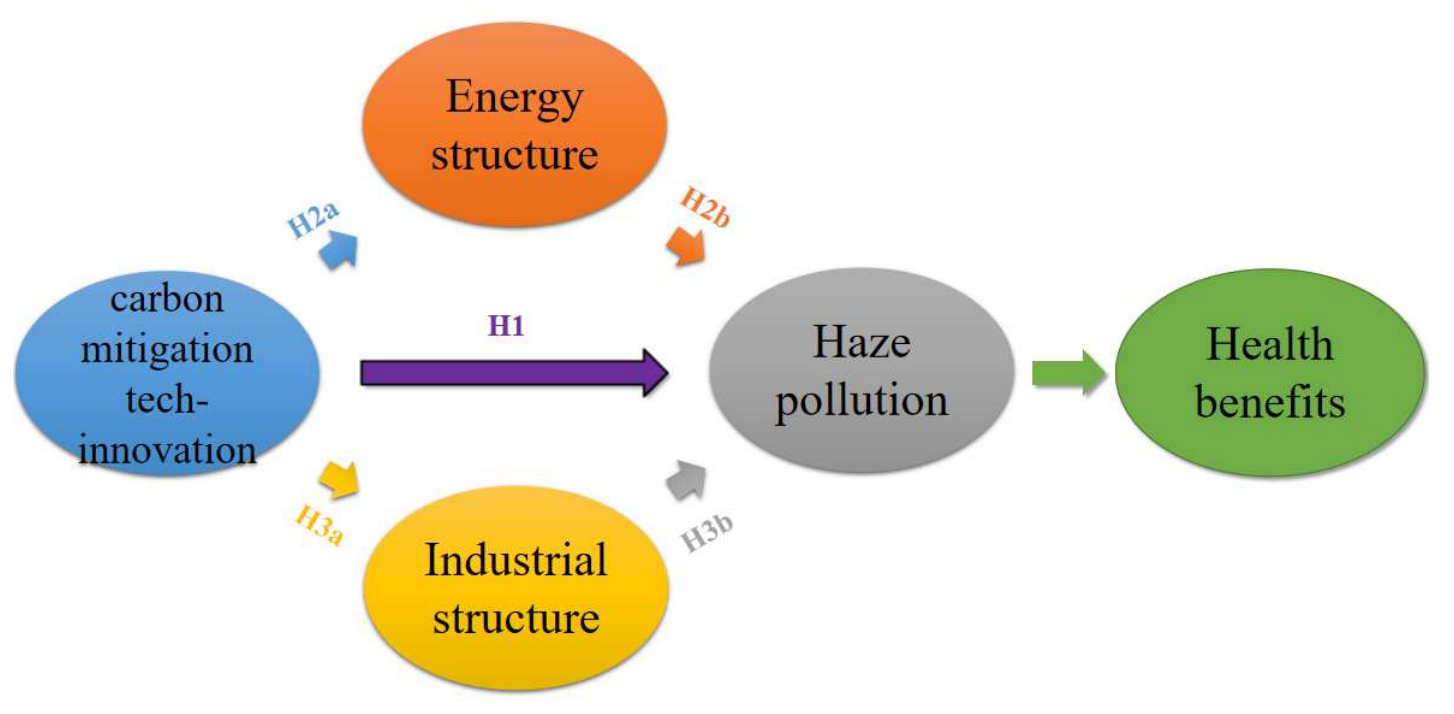

298

299

300

301

302

303

304

305

306

307

308

309

310

311

312

Fig. 2. The methodological framework of theoretical hypotheses.

\section{Data descriptive and model specification}

\subsection{Variables and data description}

\subsubsection{Haze Pollution}

Haze pollution is often measured in terms of fine particles $P M_{2.5}$ (Zhang et al.,2018). Data were collected using raster data from Dalhousie University Atmospheric Composition Analysis Group based on annual mean global $P M_{2.5}$ concentrations monitored by satellites, data from the group's official website (http://fizz.phys.dal.ca/ atmos/martin/? Page_id =140), and use ArcGIS software to analyze it into the annual average $P M_{2.5}$ concentration value of China's provinces from 2004 to 2016. The reasons are as follows: First, China has not released long-term and reliable $P M_{2.5}$ concentration data, which was only started in 2013 at the earliest, and $P M_{2.5}$ detection in China is still mainly based on fixed site monitoring, with a very limited number (Lin et al.,2018). Second, although the actual monitoring data collected by the ground observation stations can more truly reflect the haze pollution situation of the stations by taking advantage of their own advantages, the 
concentration distribution of $P M_{2.5}$ is not limited to a single station, and there are significant spatial differences in the same region. Therefore, if the station data of the ground monitoring stations are used for analysis, It will only provide a rough measure of the haze pollution situation in the region, which will bring a large error to the actual estimation results. In contrast, satellite-based data on the concentration of haze pollution $\left(P M_{2.5}\right)$ can give a more accurate picture of an area's $P M_{2.5}$ concentration. Similarly, due to the above reasons, this data has been widely used in most existing studies (Han et al.,2017; Yang et al.,2020; Feng et al., 2021).

\subsection{2. carbon mitigation tech-innovation}

Carbon mitigation tech-innovation (CMTI) is measured by the number of domestic Chinese patent applications in the Y02 category of the $\mathrm{CPC}(\mathrm{Cooperative}$ Patent Classification) jointly issued by the European Patent Office (EPO) and the United States Patent Office (USPTO) in 2013. CPC combines the strengths of the United States Patent Classification System (USPC), the European Patent Classification System (ECLA) and the International Patent Classification System (IPC) while providing technical, functional and product application information. In order to subdivide carbon emission reduction technologies into clean technologies and grey technologies, each subcategory is identified based on the Y02 category in the cooperative patent classification and according to the concepts of clean and grey low-carbon technologies in the existing literature (Wang et al.,2020a). In this study, the whole Y02 category represents low-carbon technologies. The patents with CPC code in Schedule 1 belong to clean technologies, while the rest of the Y02 patents 
belong to gray technologies.

3.1.3. Energy structure and industrial structure

Energy structure (ES). China's energy structure dominated by coal consumption is an important cause of air pollution and greenhouse gas emissions (Liu et al.,2016b). Since 1978, China's coal consumption has gradually exceeded that of all countries in the world and continues to grow (Hao et al.,2016). This phenomenon is closely related to the increasingly serious air pollution in China. Therefore, the proportion of coal consumption in the total energy consumption is used to measure the energy consumption structure, and it is used as an intermediary variable to explore the intermediary effect between carbon mitigation tech-innovation and haze pollution.

Industrial structure (IS). Enterprises with high carbon emissions are always in urgent need of rectification and elimination on the road of industrial structure optimization in China. The depth of industrialization has led to serious problems in China's current industrial structure, among which the excessively large proportion of the secondary industry is a very prominent problem (Lin and Zhu,2019a). These problems will indirectly damage China's environment and ecology. It has a serious impact on air pollution in China. Therefore, this paper uses the proportion of the added value of the secondary industry to measure the industrial structure (IS), and also takes it as an intermediary variable to explore its mediating effect between carbon mitigation tech-innovation and haze pollution.

\subsubsection{Control variables}


On the basis of existing studies, this paper selects four variables as control

359 variables: population density (POP), economic growth (PGDP), openness to the 360 outside world (FDI) and environmental regulation (MR).

(1) Population density (POP). In this paper, the ratio of population size to administrative area is used as a proxy index of population size. Based on relevant studies (Shao et al.,2011; Fan and Xu.,2020) found that the scale effect brought by large population agglomeration usually leads to environmental deterioration and positive.

(2) Economic development level (PGDP). This paper uses the per capita GDP to measure the level of regional economic development. According to existing studies, there are mainly two views on the relationship between economic development level and environmental quality: On the one hand, the level of regional economic development shows Kuznets effect in the process of affecting environmental pollution,

372 that is, the environmental quality will deteriorate first and then gradually improve 373 with the improvement of economic development level, showing an inverted "U" 374 -shaped nonlinear relationship (Xu et al.,2016; Wang and Fang.2016; Gan et al.,2020);

375 On the other hand, economic scale effect is the dominant factor of climate change and 376 haze pollution, so they show a linear relationship (Kearsley and Riddel.2010), which 377 does not conform to Kuznets effect. Referred to relevant literature (Lin and 378 Zhu,2019b), the primary and secondary items of economic growth were included in the research on the relationship between the level of economic development and haze 
pollution, and the two main viewpoints on the relationship between the level of economic development and haze pollution were tested respectively.

(3) Openness (FDI). In this paper, the ratio of the actual utilized foreign direct investment to the regional GDP in each administrative division is used to measure, and it is converted into RMB by the exchange rate between US dollar and RMB in that year. Openness plays an important role in China's environmental research and is an important factor that cannot be ignored. However, the relevant research conclusions are not unified, mainly manifested in two hypotheses: the "pollution heaven" hypothesis that FDI will worsen environmental quality. In order to accelerate regional economic development, each region will lower its environmental protection standards to attract more foreign investment, and accelerate the development and utilization of natural resources to produce more highly polluting products. Therefore, such regions are more engaged in the production of products with high energy consumption and high emission. It also exports resource-consuming and environment-polluting products (Asumadu-Sarkodie at al.,2020). Continued decline in environmental standards will exacerbate the problem of environmental degradation by intensifying regional competition to the bottom. The pollution halo hypothesis holds that FDI can improve regional environmental problems in three main aspects. First of all, the utilization of FDI will further alleviate the environmental pollution in the region while improving the income level of local residents. The "polluted paradise" will not last long (Opoku et al.,2021). Secondly, as foreign-funded enterprises are able to implement stricter environmental protection standards, a large amount of foreign 
investment can reduce pollution emissions in the places where the capital is used (Luo et al.,2021). Last but not least, the new technologies brought by foreign investment are also conducive to further improving the local environmental quality. The introduction of environmentally friendly technologies and products by the inflow of foreign capital can improve the environmental welfare of the destination (Khan et al.,2021).

(4) Environmental Regulation (MR). This paper controls the impact of command-and-control regulation (CR) and market-based regulation (MR), two major types of environmental regulation in China. Command-and-control regulation $(\mathrm{CR})$ is measured by pollutant emission intensity, and market-based regulation (MR) is measured by pollutant emission charge. In recent years, the Chinese government has recognized the huge environmental pressure China is facing, and has taken different measures to strictly regulate enterprises. These environmental regulations have been proved by a large number of studies to play an important role in alleviating haze pollution (Zhang et al.,2020; Zhang et al.,2020; Zhou et al.,2021). According to Ren et al.(2018a) and Wang et al.(2020),command-and-control regulation (CR) can be measured by the following formula.

First, the four pollutants, solid waste, sulfur dioxide $\left(\mathrm{SO}_{2}\right)$, wastewater and flue gas, are treated according to Eq.(1)

$$
U E_{i j}^{s}=\frac{U E_{i j}-\min \left(U_{j}\right)}{\max \left(U_{j}\right)-\min \left(U_{j}\right)}
$$

Where, $\max \left(U_{j}\right)$ and $\min \left(U_{j}\right)$ are respectively the maximum and minimum values of $j$ pollutants in each province each year. $U E_{i j}$ presents $j$ pollutant 
discharge per unit output value in province $i$, and $U E_{i j}^{s}$ is the intensity of discharge treated by linear standardization. The adjustment coefficient of the four pollutants, such as Eq. (2), reflects the differences of the four pollutants in different provinces.

$$
W_{j}=\frac{U E_{i j}}{\overline{U E_{i j}}}
$$

Where, $\overline{U E_{i j}}$ represents the average unit output value of $j$ pollutant discharge in all provinces, and $W_{j}$ is the weight of $j$ pollutant discharge in each provinces. The synthesis method, which creates a comprehensive index of various pollutant discharges, is shown in Eq. (3), and $E R_{i}$ represents the intensity of environmental regulation.

$$
E R_{i}=\frac{1}{4} \sum_{j=1}^{4} W_{j} U E_{i j}^{s}
$$

At present, the market-based regulation (MR) is mainly measured by sewage charges in China (Zhao and Sun. 2015; Ren et al. , 2018b). So we also adopt this method, and sewage charges are taken 2000 as the base year for the correction.

\subsubsection{Date source}

In this paper, the data of 30 provinces from 2004 to 2016 were selected for the research (due to the lack of data of Xizang, Hong Kong, Macao and Taiwan, the data were not taken into account). Among them, the (Y02) patent data used by provinces and cities to measure innovation in low-carbon technology was obtained from Incopat database (https://www.incopat.com/). The population data of each region, per capita GDP, actual utilized foreign capital data and secondary industry added value data are from China Statistics Yearbook. Energy consumption data are from China Energy 
Table 1

\begin{tabular}{|c|c|c|c|c|c|c|}
\hline variables & meaning & Obs. & Mean & SD & Min & Max \\
\hline $\operatorname{lnPM}$ & Haze pollution & 390 & 3.398 & 0.547 & 1.938 & 4.406 \\
\hline $\operatorname{lnCMTI}$ & $\begin{array}{c}\text { Carbon mitigation } \\
\text { tech-innovation }\end{array}$ & 390 & 6.499 & 1.529 & 1.792 & 9.911 \\
\hline $\operatorname{lnGT}$ & Clean technology & 390 & 6.218 & 1.550 & 1.609 & 9.643 \\
\hline $\operatorname{lnCT}$ & Grey technology & 390 & 5.044 & 1.515 & 0 & 8.462 \\
\hline ES & Energy structure & 390 & 0.649 & 0.165 & 0.121 & 0.938 \\
\hline IS & Industrial structure & 390 & 0.949 & 0.506 & 0.494 & 4.165 \\
\hline $\ln P G D P$ & GDP per capita & 390 & 10.26 & 0.669 & 8.370 & 11.68 \\
\hline $\ln \mathrm{POP}$ & Population density & 390 & 5.429 & 1.268 & 2.046 & 8.249 \\
\hline FDI & $\begin{array}{l}\text { Ratio of foreign direct } \\
\text { investment }\end{array}$ & 390 & 2.605 & 2.287 & 0.0386 & 14.61 \\
\hline $\operatorname{lnCR}$ & $\begin{array}{l}\text { Command-and-control } \\
\text { regulation }\end{array}$ & 390 & 5.467 & 1.786 & -6.908 & 7.935 \\
\hline $\ln M R$ & $\begin{array}{l}\text { Market-based } \\
\text { regulation }\end{array}$ & 390 & 9.670 & 0.984 & 6.520 & 11.85 \\
\hline
\end{tabular}

The descriptive statistics of explained variable and explanatory variables.

\subsection{Econometric model specification}

453 influencing factors mainly centers on STIRPAT model and EKC hypothesis, this paper

454 discusses the effect of carbon mitigation tech-innovation on reducing haze pollution

455 by combining them, and analyzes the mediation effect of industrial structure and energy structure under the direct effect in detail. 
Holdren (1971), and the traditional IPAT model is defined as Eq. (4). However, later studies found the limitations of the IPAT model (Tursun et al.,2015). Therefore, Dietz and Rosa (1994) further developed this model on this basis. A Modified Stirpat Model as Eq. (5)

$$
\begin{aligned}
& I=P A T \\
& I_{i t}=a P_{i t}^{b} A_{i t}^{c} T_{i t}^{d} e
\end{aligned}
$$

Where, $I_{i t}, P_{i t}, A_{i t}, \quad T_{i t}$ represent the environmental impact, population size, per capita wealth and technological level of province $i$ in year $t$, respectively. Parameter $a$ denotes the constant term. $b, c, d$ respectively represent the population size, per capita wealth and technical level, $e$ represents the error term. Take natural logarithms from both sides of the model and turn the model into a linear form to obtain Eq. (6).

$$
\operatorname{LnI}_{i t}=\alpha+b \operatorname{Ln} P_{i t}+c \operatorname{LnA} A_{i t}+d \operatorname{Ln} T_{i t}+e_{i t}
$$

One of the major advantages of STIRPAT model is that it can not only estimate the parameters of the model, but also change the environmental factors appropriately. Therefore, Eq. (7) can be preliminarily rewritten as follows:

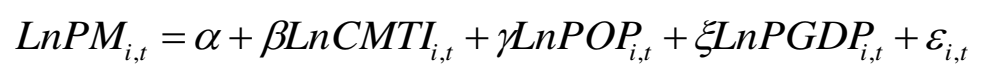

Where $i$ represents the province, $t$ represents the year, $P M$ represents haze pollution ( $P M_{2.5}$ concentration), $C M T I$ represents carbon mitigation tech-innovation (measured by Y02 category patents), POP represents population size (measured by provincial population density), and $P G D P$ represents per capita wealth (measured by provincial per capita $P G D P) . \beta, \gamma, \lambda$ are the coefficients of $C M T I, P O P$ and $P G D P$ respectively, $\alpha$ is the constant term. $\varepsilon_{i, t}$ represents the error term. 
481

482

483

484

485

486

487

488

489

490

491

492

493

494

495

496

497

498

499

500

501

basis of Kuznets (1955), aiming to reveal the inverted U-shaped relationship between

economic development and environment. At present, most scholars incorporate the

EKC hypothesis when studying environmental problems (Lin and Zhu.2019c;Zhao et

al.,2020). Therefore, we follow the classical EKC hypothesis and make appropriate changes of STIRPAT model to study the impact of carbon mitigation tech-innovation on haze pollution, as shown in Eq. (8) :

$$
\begin{aligned}
& \operatorname{LnPM}_{i, t}=\alpha+\beta \operatorname{LnCMTI} I_{i, t}+\gamma \operatorname{LnPOP} P_{i, t}+\xi \operatorname{LnPGDP_{i,t}}+\xi_{1}\left(\operatorname{LnPGDP}_{i, t}\right)^{2} \\
& +\xi_{2} F D I_{i, t}+\xi_{3} L_{n M R_{i, t}}+\xi_{4} \operatorname{LnCR}_{i, t}+\lambda_{i}+\mu_{i}+\varepsilon_{i, t}
\end{aligned}
$$

Where, $i$ represents the province, $t$ represents the year, $\alpha_{1}, \beta, \gamma, \xi_{i}$ are the coefficients of each variable, $\lambda_{i}$ and $\mu_{i}$ represent individual effect and time effect respectively, $\alpha$ is the constant term.

In order to test the mediating role of the industrial structure and energy structure proposed above in the impact of technological innovation coping with carbon emission reduction on haze pollution, the following static panel model is preliminarily set.

$$
\operatorname{LnPM}_{i, t}=\alpha_{0}+\alpha_{1} \operatorname{LnCMTI}_{i, t}+\alpha_{2} X_{i, t}+\lambda_{i}+\mu_{i}+\varepsilon_{i . t}
$$

$$
\operatorname{LnPM} M_{i, t}=\beta_{0}+\beta_{1} E S_{i, t}+\beta_{2} X_{i . t}+\lambda_{i}+\mu_{i}+\varepsilon_{i, t}
$$

$$
E S_{i, t}=\delta_{0}+\delta_{1} \operatorname{LnCMTI}_{i, t}+\delta_{2} X_{i, t}+\lambda_{i}+\mu_{i}+\varepsilon_{i, t}
$$

$$
\operatorname{LnPM}_{i, t}=\rho_{0}+\rho_{1} \operatorname{LnCMTI}_{i, t}+\rho_{2} E S_{i, t}+\rho_{3} X_{i, t}+\lambda_{i}+\mu_{i}+\varepsilon_{i, t}
$$

$$
\operatorname{LnPM}_{i, t}=\varsigma_{0}+\varsigma_{1} I S_{i, t}+\varsigma_{2} X_{i, t}+\lambda_{i}+\mu_{i}+\varepsilon_{i, t}
$$

$$
I S_{i, t}=\varphi_{0}+\varphi_{1} \operatorname{LnCMTI}_{i, t}+\varphi_{2} X_{i, t}+\lambda_{i}+\mu_{i}+\varepsilon_{i, t}
$$


In regression equations (9) (15), $X_{i, t}$ represents the control variable, including LnPGDP, $(\operatorname{LnPGDP})^{2}, \operatorname{LnPOP}, F D I, L n M R$ and LnCR. $\alpha, \beta, \delta, \rho, \varsigma, \varphi$ and $\zeta$ are the coefficients of each variable. If $\alpha, \delta$ and $\varphi$ are significant, it indicates that $\mathbf{H 1}, \mathbf{H 2}$ and $\mathbf{H 3}$ are true.

In this paper, the mediation effect test will first use the Causal steps approach (Baron and Kenny.1986). The inspection process is divided into three steps. The first and second steps are to test H1, H2a and H3a, which $\alpha_{1}$ should be significant. The third step is to test whether $\delta_{1}, \rho_{2}$ and $\varphi_{1}, \zeta_{2}$ are significant. If significant, $\mathbf{H 2 c}$ and $\mathbf{H 3 c}$ are true; if at least one of them is not significant, Sobel test is required (Sobel.1988).

\section{Estimation results}

In this paper, classical econometric models are used for regression analysis. First, Hausmann test is used to select fixed effect models and random effect models. The test results are shown in Table 2.

\subsection{Impact of carbon mitigation tech-innovation on haze pollution}

According to the estimated results of Model 1 in Table 2, at the significance level of $1 \%$, the impact coefficient of carbon emission reduction technological innovation on haze pollution is -0.066 , that is, each $1 \%$ increase in carbon emission reduction technological innovation can reduce haze pollution by $0.066 \%$. This test result supports $\mathrm{H} 1$. It shows that the technological innovation of carbon emission reduction in China in recent years can effectively curb haze pollution while coping 
523 with climate change, bringing about common benefits of air quality and improvement

524 of residents' health. In addition, it can be seen from the estimated results of Tabel 4

525 and Table 5 that every $1 \%$ increase in gray technology innovation can bring about a

$5260.066 \%$ reduction in haze pollution. Every $1 \%$ increase in clean technology

527 innovation can reduce smog pollution by $0.029 \%$. It shows that both grey technology

528 innovation and clean technology innovation can effectively restrain haze pollution,

529 but grey technology innovation plays a greater role than clean technology innovation.

530 Table 2

531 Results of mediating effects

\begin{tabular}{cccccc}
\hline Variables & $\operatorname{lnPM}$ & $\mathrm{ES}$ & $\operatorname{lnPM}$ & $\mathrm{IS}$ & $\ln \mathrm{PM}$ \\
\cline { 2 - 6 } & Model 1 & Model 2 & Model 3 & Model 4 & Model 5 \\
\hline lnCMTI & $-0.066^{* * *}$ & $-0.026^{* * *}$ & $-0.058^{* * *}$ & $-0.124^{* * *}$ & $-0.059^{* * *}$ \\
& $(-3.17)$ & $(-2.74)$ & $(-2.76)$ & $(-4.23)$ & $(-2.77)$ \\
ES & & & $0.324^{* * *}$ & & \\
IS & & & $(2.75)$ & & \\
& & & & 0.057 \\
lnPGDP & $1.464^{* * *}$ & $0.244^{*}$ & $1.543^{* * *}$ & 0.010 & $1.463 * * *$ \\
& $(4.62)$ & $(1.69)$ & $(4.89)$ & $(0.02)$ & $(4.62)$ \\
lnPGDP2 & $-0.063^{* * *}$ & $-0.014^{*}$ & $-0.068^{* * *}$ & -0.032 & $-0.065^{* * *}$ \\
& $(-3.96)$ & $(-1.87)$ & $(-4.25)$ & $(-1.41)$ & $(-4.07)$ \\
lnPOP & $0.643^{* * *}$ & $0.224^{* * *}$ & $0.571^{* * *}$ & $1.037^{* * *}$ & $0.702^{* * *}$ \\
& $(3.76)$ & $(2.87)$ & $(3.33)$ & $(4.30)$ & $(4.00)$ \\
FDI & $0.011^{* *}$ & 0.002 & $0.010^{* *}$ & 0.002 & $0.011^{* *}$ \\
& $(2.24)$ & $(0.87)$ & $(2.13)$ & $(0.32)$ & $(2.27)$ \\
\hline lnMR & $-0.026^{*}$ & $-0.030^{* * *}$ & -0.017 & $-0.042^{* *}$ & $-0.029^{*}$ \\
& $(-1.80)$ & $(-4.51)$ & $(-1.11)$ & $(-2.04)$ & $(-1.95)$ \\
lnCR & -0.001 & -0.003 & -0.000 & $0.048^{* * *}$ & -0.004 \\
& $(-0.21)$ & $(-1.20)$ & $(-0.03)$ & $(6.31)$ & $(-0.67)$ \\
Constant & $14.923^{* * *}$ & 0.635 & $14.718^{* * *}$ & -1.114 & $14.987^{* * *}$ \\
& $(6.44)$ & $(0.60)$ & $(6.41)$ & $(-0.34)$ & $(6.48)$ \\
Hausman & $\mathrm{P}=0.0000$ & $\mathrm{P}=0.0002$ & $\mathrm{P}=0.0000$ & $\mathrm{P}=0.0000$ & $\mathrm{P}=0.0000$ \\
Rbservations & 390 & 390 & 390 & 390 & 390 \\
r2_a & 0.431 & 0.395 & 0.443 & 0.713 & 0.434 \\
& 0.350 & 0.309 & 0.363 & 0.672 & 0.353 \\
& & & & &
\end{tabular}


532

533

534

535

\begin{tabular}{cccc}
$\mathrm{F}$ & 13.57 & 11.70 & 13.52 \\
\hline Notes: t-statistics in parentheses.all results are calculated by Stata 16.0.
\end{tabular}

$* \mathrm{p}<0.1$.

$* * \mathrm{p}<0.05$.

$* * * \mathrm{p}<0.01$.

\subsection{Impact of carbon mitigation tech-innovation on energy structure and} industrial structure

According to the estimated results of Model 2 and Model 4 in Table 2, it is found that every $1 \%$ increase in carbon mitigation tech-innovation can significantly reduce the proportion of coal's energy consumption by $0.026 \%$, and the industrial proportion of secondary industry's added value by $0.124 \%$. In order to improve China's energy structure and industrial structure. This test result supports $\mathrm{H} 2 \mathrm{a}$ and $\mathrm{H} 3 \mathrm{a}$. It shows that China's carbon mitigation tech-innovation not only improves air quality directly, but also promotes a more systematic structural green transformation, including energy and industrial structure. From the estimation results of Tabel 4 and Table 5, it can be found that both clean technology innovation and grey technology innovation can effectively promote the green transformation of China's energy structure and industrial structure, and grey technology innovation plays a greater role.

\subsection{Impact of industrial structure and energy structure on haze pollution}

According to the regression results of Model 1 in Table 3, at the significance level of $1 \%$, the impact coefficient of energy structure on haze pollution is 0.372 , which indicates that the energy structure is highly correlated with haze pollution, and the larger the proportion of fossil energy consumption is, the more serious the haze pollution will be, which supports H2B. Meanwhile, according to the results of Model 
5552 in Table 3, we find that at the significance level of 5\%, the influence coefficient of

556 industrial structure on haze pollution is 0.081 , indicating that industrial structure is

557 also highly correlated with haze pollution. The excessive proportion of added value in

558 the secondary industry leads to the decline of air quality. The test results support H3b.

559 Based on the above tests, it is found that unreasonable energy structure and industrial

560 structure are both important causes of haze pollution.

561 Table 3

562 Impact of industrial structure and energy structure on haze pollution

\begin{tabular}{lcc}
\hline Variables & $\operatorname{lnPM}$ & $\operatorname{lnPM}$ \\
\cline { 2 - 3 } & Model 1 & Model 2 \\
\hline ES & $0.372^{* * *}$ & \\
& $(3.16)$ & \\
IS & & $0.081^{* *}$ \\
& & $(2.13)$ \\
lnPGDP & $1.722^{* * *}$ & $1.629^{* * *}$ \\
& $(5.52)$ & $(5.19)$ \\
lnPGDP2 & $-0.074^{* * *}$ & $-0.072^{* * *}$ \\
& $(-4.66)$ & $(-4.48)$ \\
lnPOP & $0.615^{* * *}$ & $0.782^{* * *}$ \\
& $(3.57)$ & $(4.47)$ \\
FDI & $0.011^{* *}$ & $0.012^{* *}$ \\
& $(2.41)$ & $(2.58)$ \\
lnMR & -0.015 & $-0.029 * *$ \\
& $(-0.98)$ & $(-1.97)$ \\
lnCR & -0.001 & -0.004 \\
& $(-0.27)$ & $(-0.61)$ \\
\hline Constant & $15.762^{* * *}$ & $16.082^{* * *}$ \\
& $(6.89)$ & $(6.99)$ \\
Observations & 390 & 390 \\
R-squared & 0.430 & 0.422 \\
r2_a & 0.350 & 0.340 \\
F & 13.56 & 13.08 \\
\hline
\end{tabular}




\section{of carbon mitigation tech-innovation on haze pollution}

\subsubsection{Overall carbon mitigation tech-innovation}

According to Models 1 and 2 in Table 2, both the coefficients of energy structure on haze pollution caused by carbon mitigation tech-innovation are negative at the significance level of $1 \%$, that is, $\alpha_{1}$ and $\delta_{1}$ are significant. According to Model 3 in Table 2, the coefficients of carbon mitigation tech-innovation and energy structure are both significant at the significance level of $1 \%$, that is, $\alpha_{1}$ and $\delta_{1}$ are significant. According to the Causal steps approach (Baron and Kenny.1986), if both are significant, it indicates that the energy structure plays a partial mediating role in the impact of carbon mitigation tech-innovation on haze pollution. According to Model 4 in Table 2, the influence coefficient of carbon emission reduction technological innovation on industrial structure is negative at the significance level of $1 \%$. However, as the relationship between industrial structure and haze pollution in Model 5 is not significant, Sobel test is needed (Sobel.1988). The verification results show that the $\mathrm{Z}$ value of the mediating effect of industrial structure is -2.041 . Therefore, the mediating effect of industrial structure is significant, and the proportion of the mediating effect in the total effect is $50.08 \%$, which supports $\mathrm{H} 2 \mathrm{c}$ and H3c. This result shows that China's carbon mitigation tech-innovation can alleviate haze pollution by improving the energy structure and industrial structure, and bring about synergistic effect of air quality. In this process, the energy structure plays a greater intermediary role and the effect is more obvious. The reason is that carbon reduction technology innovation can not only improve the efficiency of fossil energy and reduce the use of such energy, but 
587

588

589

590

591

592

593

594

595

596

597

also increase the proportion of renewable energy. The green transformation of energy structure can more directly reduce pollution gas emissions and curb haze pollution. Compared with the energy structure, the industrial structure involves a wider range, and it is slower for technological innovation to reduce haze pollution through the green transformation of the industrial structure.

\subsubsection{Grey technology innovation}

According to Models 1,2 and 3 in Table 4, its coefficients are significant at the significance level of $1 \%$ and $5 \%$, indicating that energy structure plays a partial mediating role in the impact of grey technology innovation on haze pollution. Since the relationship between industrial structure and haze pollution in Model 5 is not significant, we also apply Sobel test. The results show that the $\mathrm{Z}$ value of the mediating effect of the industrial structure is -2.052 , indicating that the industrial structure plays a partial mediating role in the impact of grey technology innovation on haze pollution, and the mediating effect accounts for $62.2 \%$ of the total effect. As a result, China in recent years, a lot of grey technology innovation not only direct inhibition of smog pollution, but also can improve efficiency of energy utilization, is advantageous to the reduction in the petrochemical industrial production energy consumption and emissions of polluting gases (such as $\mathrm{NO}_{x}, \mathrm{SO}_{2}$ etc.), so as to improve the energy structure and promote the green transformation of industrial structure, to achieve indirect inhibition of smog pollution and improve air quality.

\section{Table 4}

The mediating effect of ES and IS in the impact of Grey technology innovation on haze pollution 


\begin{tabular}{|c|c|c|c|c|c|}
\hline \multirow[t]{2}{*}{ Variable } & $\ln P M$ & ES & $\operatorname{lnPM}$ & IS & $\ln P M$ \\
\hline & Model 1 & Model 2 & Model 3 & Model 4 & Model 5 \\
\hline \multirow[t]{2}{*}{$\operatorname{lnGT}$} & $-0.066^{* * *}$ & $-0.023 * *$ & $-0.059 * * *$ & $-0.117 * * *$ & $-0.060 * * *$ \\
\hline & $(-3.36)$ & $(-2.58)$ & $(-2.98)$ & $(-4.19)$ & $(-2.97)$ \\
\hline \multirow[t]{2}{*}{ ES } & & & $0.323 * * *$ & & \\
\hline & & & $(2.75)$ & & \\
\hline \multirow[t]{2}{*}{ IS } & & & & & 0.055 \\
\hline & & & & & $(1.45)$ \\
\hline \multirow[t]{2}{*}{$\operatorname{lnPGDP}$} & $1.430 * * *$ & $0.247^{*}$ & $1.510^{* * *}$ & 0.025 & $1.432 * * *$ \\
\hline & $(4.50)$ & $(1.70)$ & (4.78) & $(0.06)$ & $(4.51)$ \\
\hline \multirow[t]{2}{*}{ lnPGDP2 } & $-0.061 * * *$ & $-0.014^{*}$ & $-0.066^{* * *}$ & -0.034 & $-0.063 * * *$ \\
\hline & $(-3.83)$ & $(-1.90)$ & $(-4.13)$ & $(-1.51)$ & $(-3.94)$ \\
\hline \multirow[t]{2}{*}{$\ln \mathrm{POP}$} & $0.670^{* * *}$ & $0.236^{* * *}$ & $0.593 * * *$ & $0.983^{* * *}$ & $0.724^{* * *}$ \\
\hline & (3.94) & $(3.04)$ & $(3.48)$ & $(4.09)$ & $(4.16)$ \\
\hline \multirow[t]{2}{*}{ FDI } & $0.011 * *$ & 0.002 & $0.010 * *$ & 0.002 & $0.011^{* *}$ \\
\hline & $(2.29)$ & $(0.94)$ & $(2.17)$ & $(0.23)$ & $(2.32)$ \\
\hline \multirow[t]{2}{*}{$\operatorname{lnMR}$} & $-0.026^{*}$ & $-0.030 * * *$ & -0.016 & $-0.043 * *$ & $-0.029^{*}$ \\
\hline & $(-1.78)$ & $(-4.48)$ & $(-1.10)$ & $(-2.08)$ & $(-1.93)$ \\
\hline \multirow[t]{2}{*}{$\operatorname{lnCR}$} & -0.001 & -0.003 & 0.000 & $0.049 * * *$ & -0.004 \\
\hline & $(-0.16)$ & $(-1.13)$ & $(0.00)$ & $(6.40)$ & $(-0.63)$ \\
\hline \multirow[t]{2}{*}{ Constant } & $14.904 * * *$ & 0.683 & $14.683^{* * *}$ & -0.995 & $14.959 * * *$ \\
\hline & $(6.45)$ & $(0.65)$ & $(6.41)$ & $(-0.31)$ & $(6.48)$ \\
\hline Observations & 390 & 390 & 390 & 390 & 390 \\
\hline R-squared & 0.433 & 0.393 & 0.445 & 0.712 & 0.436 \\
\hline r2_a & 0.353 & 0.308 & 0.365 & 0.672 & 0.355 \\
\hline $\mathrm{F}$ & 13.68 & 11.63 & 13.63 & 44.43 & 13.15 \\
\hline
\end{tabular}

609

Notes: t-statistics in parentheses.all results are calculated by Stata 16.0.

$610 * \mathrm{p}<0.1$.

$611 * * \mathrm{p}<0.05$.

$612 * * * \mathrm{p}<0.01$.

616 coefficients of clean technology innovation in Model 3 are not. It is noteworthy that

617 the coefficient of energy structure is very significant. According to Baron and 618 Kenny.1986, if in Eq.(9) $\sim$ Eq.(12), $\alpha_{1}, \delta_{1}$ and $\rho_{2}$ are significant, while $\rho_{1}$ is not, it 619 indicates that the energy structure plays a complete intermediary role in the impact of 
6214 and Model 5, industrial structure has no obvious mediating effect on the impact of

622 clean technology innovation on haze pollution. Therefore, China's clean technology

623 innovation in recent years is mainly through the green transformation of the energy

624 structure to curb haze pollution. The reason may be that clean technology is

625 zero-carbon technology, which can increase the use of clean energy and replace the

626 consumption of coal and other fossil energy, which is conducive to improving China's

627 energy structure and indirectly inhibiting haze pollution. However, the adjustment of

628 industrial structure may require longer time and more investment in technological

629 innovation. Currently, the number of clean technology innovations in China is not

630 enough (as shown in Fig.1), so the industrial structure has not yet played an

631 intermediary role.

\section{Table 5}

633 The mediating effect of ES and IS in the impact of clean technology innovation on haze pollution

\begin{tabular}{|c|c|c|c|c|c|}
\hline \multirow[t]{2}{*}{ Variables } & $\operatorname{lnPM}$ & ES & $\operatorname{lnPM}$ & IS & $\operatorname{lnPM}$ \\
\hline & Model 1 & Model 2 & Model 3 & Model 4 & Model 5 \\
\hline \multirow[t]{2}{*}{$\operatorname{lnCT}$} & $-0.029 *$ & $-0.016^{* *}$ & -0.023 & $-0.070 * * *$ & -0.024 \\
\hline & $(-1.71)$ & $(-2.15)$ & $(-1.37)$ & $(-2.93)$ & $(-1.40)$ \\
\hline \multirow[t]{2}{*}{ ES } & & & $0.353 * * *$ & & \\
\hline & & & $(2.98)$ & & \\
\hline \multirow[t]{2}{*}{ IS } & & & & & 0.072 \\
\hline & & & & & $(1.39)$ \\
\hline \multirow[t]{2}{*}{$\operatorname{lnPGDP}$} & $1.613 * * *$ & 0.193 & $1.681 * * *$ & 0.265 & $1.594 * * *$ \\
\hline & (5.11) & $(1.36)$ & $(5.38)$ & $(0.59)$ & $(5.07)$ \\
\hline \multirow[t]{2}{*}{ lnPGDP2 } & $-0.069 * * *$ & -0.011 & $-0.073 * * *$ & -0.021 & $-0.071 * * *$ \\
\hline & $(-4.33)$ & $(-1.57)$ & $(-4.61)$ & $(-0.93)$ & $(-4.43)$ \\
\hline \multirow[t]{2}{*}{$\ln \mathrm{POP}$} & $0.642 * * *$ & $0.212 * * *$ & $0.567 * * *$ & $1.076 * * *$ & $0.720 * * *$ \\
\hline & $(3.65)$ & $(2.66)$ & $(3.22)$ & (4.32) & (3.99) \\
\hline \multirow[t]{2}{*}{ FDI } & $0.011 * *$ & 0.002 & $0.011 * *$ & 0.001 & $0.011^{* *}$ \\
\hline & $(2.36)$ & $(0.92)$ & $(2.24)$ & $(0.20)$ & $(2.39)$ \\
\hline
\end{tabular}




\begin{tabular}{cccccc}
$\operatorname{lnMR}$ & $-0.027^{*}$ & $-0.031^{* * *}$ & -0.016 & $-0.040^{*}$ & $-0.030^{* *}$ \\
& $(-1.84)$ & $(-4.57)$ & $(-1.09)$ & $(-1.90)$ & $(-2.03)$ \\
$\operatorname{lnCR}$ & -0.000 & -0.003 & -0.001 & $0.049^{* * *}$ & -0.004 \\
& $(-0.08)$ & $(-1.16)$ & $(-0.10)$ & $(6.30)$ & $(-0.69)$ \\
Observations & 390 & 390 & 390 & 390 & 390 \\
R-squared & 0.419 & 0.390 & 0.434 & 0.705 & 0.425 \\
r2_a & 0.337 & 0.304 & 0.352 & 0.663 & 0.342 \\
F & 12.93 & 11.45 & 13.01 & 42.87 & 12.56 \\
\hline
\end{tabular}

634

635

636

637

638

639

640

641

642

643

644

645

646

647

648

649

650

651

652

653

Notes: t-statistics in parentheses.all results are calculated by Stata 16.0.

$* \mathrm{p}<0.1$.

$* * \mathrm{p}<0.05$.

$* * * \mathrm{p}<0.01$

\subsection{Control variables}

According to the test results of Model 1 in Table 2, the coefficient of population density is positive, which is significant at the significance level of $1 \%$, which indicates that the scale effect of population plays a major role. It also proves that under the fixed administrative area, the more population in each region, the more serious haze will be.

According to the general testing process of EKC hypothesis, the testing of the effect of economic growth is mainly conducted in the order of the second term and the first term.According to the test results of Model 1 in Table 2,it can be seen that the primary term of per capita GDP is positive and the secondary term is negative, and the coefficient is significant at the significance level of $1 \%$. The inverted "U" shaped relationship between regional economic growth and haze pollution is verified. It shows that the haze pollution level in the region increases first and then decreases with the continuous improvement of regional economic development level. 
654

655

656

657

658

659

660

661

662

663

664

665

666

667

668

669

670

671

672

673

674

675

indicates that the direct use of foreign capital aggravates haze pollution. It is likely that the local government, in order to increase employment and develop the local economy,implements relatively loose environmental policies, which attracts many polluting foreign enterprises and exacerbates China's haze pollution. This test result supports the"pollution heaven hypothesis", while the "pollution halo hypothesis" has not been verified.

According to the test results of Model 1 in Table 2, it is found that command-and-control regulation (CR) does not significantly improve haze pollution in China, and the coefficient of market-based regulation (MR) is significant at the significance level of $10 \%$. This indicates that Market-based regulation (MR) has a better effect on haze pollution control in China than command-and-control regulation (CR).

\section{Health Benefit Measurement}

Based on the above analysis, we use the empirical method to estimate that every $1 \%$ increase in carbon mitigation tech-innovation can reduce the haze pollution by $0.066 \%$. Next, we will draw on the existing literature to estimate the health benefits of carbon mitigation tech-innovation while reducing haze pollution.

Currently, the health benefits related to reducing haze pollution are mainly measured in terms of the number of deaths averted by reducing $P M_{2.5}$ concentration (Kamal Jyoti Maji et al.,2018; Yang et al., 2021c). Drawing on the results predicted by Kamal Jyoti Maji et al.2018, Table 6 shows the potential health benefits from a reduction in $P M_{2.5}$ concentrations by 2030 . Of these, 802,000 premature deaths would 
676

677 million premature deaths could have been prevented; If the IT-3 (15) target is set,

6785.597 million premature deaths can be avoided, indicating that the health benefits of

679 reducing $P M_{2.5}$ concentration are significant and huge. The haze pollution in this paper

680 is measured by the concentration value of $P M_{2.5}$. According to the results in Section

681

682

683

684

685

686

687

688

689

690

691

692

693

have been prevented if IT-1 (35) had been targeted; By targeting IT-2 (25), 2.574

is measured by the concentration value of $P M_{2.5}$. According to the results in Section

4.1, carbon mitigation tech-innovation can significantly reduce the concentration of $P M_{2.5}$ and inhibit haze pollution. Then we will calculate the common health benefits brought by carbon mitigation tech-innovation.

\section{Table 6}

Premature mortality averted by reducing $P M_{2.5}$ concentration under different scenarios

\begin{tabular}{ccccc}
\hline & 2016 & IT-1 & IT-2 & IT-3 \\
\cline { 2 - 5 } & scenario & 35 & 25 & 15 \\
\hline stroke & 470.2 & 429.8 & 423.8 & 141.5 \\
IHD & 299.8 & 287.5 & 253.3 & 184.8 \\
COPD & 150 & 90.8 & 69 & 42.3 \\
LC & 89.3 & 76 & 59.9 & 36 \\
Total & 964.3 & 884.1 & 706.9 & 404.6 \\
Avoidable excess & 80.2 & 257.4 & 559.7 \\
Premature mortality & & & \\
\hline
\end{tabular}

Data source: Kamal Jyoti Maji et al.,2018.https://doi.org/10.1016/j.envint.2018.09.024

Note: IHD:ischemic heart disease;COPD:chronic obstructive pulmonary disease;LC:lung cancer

According to Section 4.1, every $1 \%$ increase in carbon mitigation tech-innovation can effectively restrain $0.066 \%$ of haze pollution. In other words, it can reduce the concentration of $P M_{2.5}$ by $0.066 \%$.In 2019 , the average $P M_{2.5}$ concentration in China is $37 \mu \mathrm{g} / \mathrm{m}^{3}$.If IT-1 is to be achieved, the $P M_{2.5}$ concentration will be reduced to $35 \mu \mathrm{g} / \mathrm{m}^{3}$.According to Eq.(16), the growth rate required by carbon mitigation tech-innovation is $81.9 \%$. According to the historical data from 
694

695

696

697

698

699

700

701

702

703

704

705

706

707

708

709

710

711

712

713

714

715

2013 to 2016, IT is estimated that the growth rate of carbon mitigation tech-innovation is $131.849 \%$, which is far beyond the desired growth rate. At this rate, the $P M_{2.5}$ concentration can be reduced to $33.78 \mu \mathrm{g} / \mathrm{m}^{3}$ by 2022 , helping China to achieve IT-1 target. According to Eq.(16), the growth rate of carbon mitigation tech-innovation is $491.394 \%$. According to historical data and Eq.(17), we estimate that IT will take about 8 years, that is, until 2027. The health gains from carbon reduction technology innovations will help achieve IT-2, which will prevent 2.574 million premature deaths due to smog pollution in China. If IT-3 is to be achieved, that is, the smog concentration is reduced to $15 \mu \mathrm{g} / \mathrm{m}^{3}$, IT will take about 10 years, that is, the health benefits of carbon reduction technology innovation will prevent 5.597 million premature deaths by around 2029 .

The specific measurement method is:

$$
\begin{aligned}
& N G R_{c m t i}=1 \% \times \frac{\left(T P M C-P M C_{2019}\right) / P M C_{2019}}{0.066 \%} \\
& R G R_{c m t i}=\frac{C M T I_{2016}-C M T I_{j}}{C M T I_{j}}, j<2016
\end{aligned}
$$

Where, $N G R_{c m t i}$ represents the necessary growth rate of carbon mitigation tech-innovation, $T P M C$ represents the target $P M_{2.5}$ concentration, $P M C_{2019}$ is the $P M_{2.5}$ concentration in 2019 , and $\boldsymbol{R} G \boldsymbol{R}_{c m t i}$ is the actual growth rate of carbon mitigation tech-innovation calculated based on historical data. $C M T_{j}$ is the number of carbon mitigation tech-innovation in year $j$, where $j<2016$.

According to Eq. (16) and Eq. (17), we further deduced the general relationship between PMC and carbon mitigation tech-innovation based on 2019, as shown in Eq. (18): 
716

$T P M C=P M C_{2019} \times\left(1-\frac{N G R_{c m t i} \times 0.066 \%}{1 \%}\right) \Rightarrow T P M C=-2.442 N G R_{c m t i}+37$

Combined with Eq.(17) and Eq.(18), we compare the RGR calculated based on historical data with the NGR predicted based on the set target to calculate the time needed to achieve this target. The specific situation is shown in Fig.3.

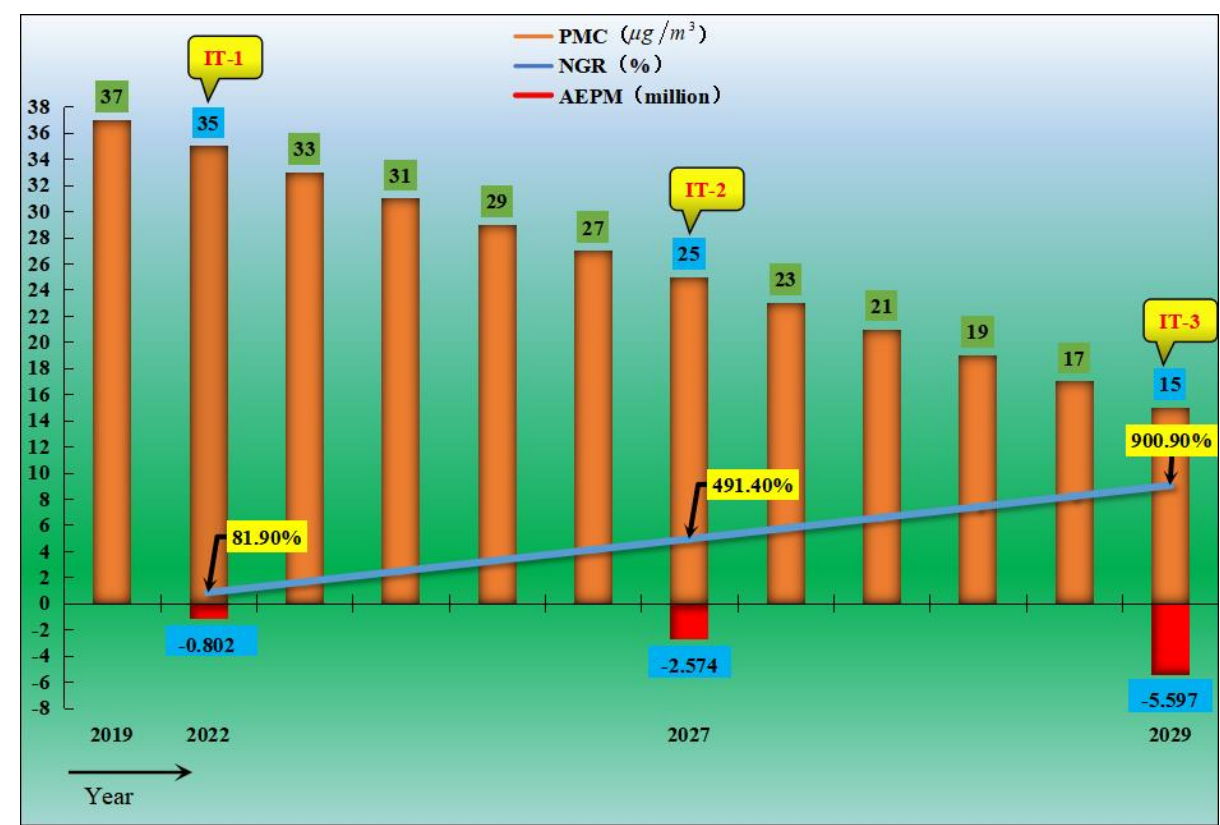

Fig.3. Health benefits from increased rates of Carbon mitigation tech-innovation

However, the above research assumptions are as follows: (1) The increase in mortality rate caused by China's aging population, changes in social life style and urbanization in the future is not taken into account. (2) The incentive effect of China's policies on climate change and air pollution on carbon mitigation tech-innovation is not considered. (3) On the basis of the first two assumptions by default, the result of their interaction is stable.

\section{Conclusions and discussion}

This paper examines the short-term local air quality gains from the overall 
innovation of carbon reduction technologies aimed at addressing long-term global climate change. In order to understand the details of the impact, on the one hand, the role of energy structure and industrial structure is included; On the other hand, we distinguish two kinds of innovation activities: clean and grey technology innovation, and analyze the heterogeneity of their impact. On this basis, we collate the relevant data of 30 Chinese provinces from 2004 to 2016, and design an econometric model for empirical analysis. The findings are as follows.

First, innovations in carbon reduction technologies that address long-term global climate change can, on the whole, bring short-term, local benefits in the form of improved air quality. Research shows that a $1 \%$ increase in the number of low-carbon patent applications can reduce smog pollution by $0.066 \%$. According to this estimate, from 2019 to 2029, China's innovation in carbon reduction technology will reduce the $P M_{2.5}$ concentration to $15 \mu \mathrm{g} / \mathrm{m}^{3}$, which will prevent 5.597 million premature deaths. Benefit analysis of air quality different from previous specific carbon emission technologies (Ou et al.,2018d; Wang et al.,2020b). According to our knowledge, this is the first time to verify the overall benefits of carbon mitigation tech-innovation on air quality improvement based on historical data, and to measure the impact on health co-benefits based on empirical results. The results of this study effectively expand the research content of "externalities" of carbon mitigation tech-innovation, and provide a reference for more reasonable calculation of short-term local costs and benefits of technology in response to climate change, as well as relevant policy formulation.

Second, carbon mitigation tech-innovation can not only directly inhibit haze 
pollution, but also indirectly inhibit haze pollution by triggering more systematic economic structure changes such as energy structure and industrial structure. The research shows that the energy structure and industrial structure have a significant intermediary role in the impact of carbon mitigation tech-innovation on haze process. However, the energy structure plays a bigger role than the improvement of the industrial structure. The reason may be that carbon mitigation tech-innovation can improve the efficiency of fossil energy, reduce its energy use, increase the consumption of renewable energy, and directly reduce $P M_{2.5}$ emissions. The industrial structure involves a wide range, and the change of industrial structure caused by carbon mitigation tech-innovation will be slower.

Third, grey technology innovation plays a more important role in improving air quality than clean technology innovation. In terms of direct effect, both types of technological innovation can effectively restrain haze pollution, but grey technological innovation has a better effect. In terms of indirect effect, grey technology innovation can inhibit haze pollution by affecting energy structure and industrial structure, while clean technology innovation can only achieve the effect of inhibiting haze pollution by improving energy structure. Therefore, grey technology may play a greater role in the economic structural change and haze impact caused by carbon mitigation tech-innovation.

Although researchers generally emphasize the limitations of grey technology innovation on long-term global climate change (Acemoglu et al,2012; Aghion et al,2016), but the logic of grey technology innovation and development may not only 
lie in the strong path-dependent effect, but also may be related to the short-term local demand for improving air quality and improving health. In fact, fossil fuels, mainly coal, still account for the majority of energy consumption in such a huge economy as China. Therefore, the effect of $P M_{2.5}$ emission reduction and economic structural change caused by gray technology progress is far higher than that of clean technology innovation. This also reflected the particularity of developing countries cope with climate change, both to support biofuels, carbon sequestration (CCS) such as cleaning, and even negative emissions technology development, also should pay attention to the development of grey technology, in order to balance the costs of carbon abatement, support the technology to address climate change on the different background pattern diversity hypothesis (Pancera, 2013).

\section{Appendix}

Table A1

The CPC code for clean technology

\begin{tabular}{|c|c|c|}
\hline Technological Domains & CPC Classes & Descriptions \\
\hline \multirow{2}{*}{ Building } & Y02B10 & Integration of renewable energy sources in buildings \\
\hline & Y02B90/1 & Applications of fuel cells in buildings \\
\hline \multirow[t]{4}{*}{$\begin{array}{l}\text { Dealing with greenhouse } \\
\text { gases }\end{array}$} & $\mathrm{Y} 02 \mathrm{C} 10$ & $\mathrm{CO}_{2}$ capture or storage \\
\hline & Y02E10 & Energy generation through renewable energy sources \\
\hline & Y02E30 & Energy generation of nuclear origin \\
\hline & Y02E50 & $\begin{array}{c}\text { Technologies for the production of fuel of non-fossil } \\
\text { origin }\end{array}$ \\
\hline \multirow[t]{4}{*}{ Energy } & Y02E60/3 & Hydrogen technology \\
\hline & Y02E60/5 & Fuel cells \\
\hline & $\mathrm{Y} 02 \mathrm{E} 70 / 1$ & $\begin{array}{l}\text { Hydrogen from electrolysis with energy of non-fossil } \\
\text { origin }\end{array}$ \\
\hline & Y02E70/2 & $\begin{array}{l}\text { Systems combining fuel cells with production of fuel } \\
\text { of non-fossil origin }\end{array}$ \\
\hline
\end{tabular}




\begin{tabular}{|c|c|c|}
\hline & Y02E70/3 & $\begin{array}{l}\text { Systems combining energy storage with energy } \\
\text { generation of non-fossil origin }\end{array}$ \\
\hline \multirow{12}{*}{ Transportation } & Y02T10/38 & $\begin{array}{l}\text { Use of non-fossil fuels in internal combustion engine } \\
\text { based vehicles }\end{array}$ \\
\hline & Y02T10/64 & $\begin{array}{l}\text { Electric machine technologies for applications in } \\
\text { electromobility }\end{array}$ \\
\hline & Y02T10/70 & Energy storage for electromobility \\
\hline & Y02T10/72 & Electric energy management in electromobility \\
\hline & Y02T10/80 & $\begin{array}{c}\text { Technologies aiming to reduce greenhouse gas } \\
\text { emissions common to all road transportation } \\
\text { technologies }\end{array}$ \\
\hline & Y02T10/90 & $\begin{array}{l}\text { Energy harvesting concepts as power supply for } \\
\text { auxiliaries' energy consumption e.g., photovoltaic } \\
\text { sun-roof }\end{array}$ \\
\hline & Y02T50/74 & $\begin{array}{l}\begin{array}{l}\text { Enabling use of bio fuels in aeronautics or air } \\
\text { transport }\end{array} \\
\end{array}$ \\
\hline & Y02T50/90 & Eco-design in aeronautics or air transport \\
\hline & $\begin{array}{c}\text { Y02T70/5218, 5227, 5236 } \\
5245,5254,58,59\end{array}$ & $\begin{array}{l}\text { Measures to reduce greenhouse gas emissions related } \\
\text { to the propulsion system of maritime or waterway } \\
\text { transport }\end{array}$ \\
\hline & Y02T90/1 & Technologies related to electric vehicle charging \\
\hline & Y02T90/3 & Application of fuel cell technology to transportation \\
\hline & Y02T90/4 & Application of hydrogen technology to transportation \\
\hline
\end{tabular}

790

791

792

793

Author contribution Shunlin Jin: Writing - original draft, Conceptualization, Methodology. Weidong Wang: Conceptualization, Project administration. Dragana Ostic: Formal analysis, Visualization. Caijing Zhang: Investigation, Data Curation. Na Lu: Formal analysis. Dong Wang: Investigation. Wenli Ni: Formal analysis

Acknowledgements I am very grateful to the editors and anonymous reviewers for reviewing this paper.

Funding This work has been supported by the Humanities and Social Science Foundation project of The Ministry of Education of China (Study on the Dynamic Capability Formation Mechanism of China's Manufacturing Clusters oriented to Sustainable Ecological Innovation, Grant No. 16YJC630125), and the Social Science Foundation project of Jiangsu Province (Study on Ecological Innovation and Building new Competitive Advantages of Jiangsu Manufacturing Clusters, grant No. 17GLB020).

Data availability The datasets generated during the current study are available in the repository of the National Bureau of Statistics of China,Incopat database,Atmospheric Composition Analysis Group, Dalhousie University,http://www.stats.gov.cn/. 


\section{Declarations}

809

810

811

812

813

814

815

816

817

818

819

820

821

822

823

824

825

826

827

828

829

830

831

832

833

834

835

836

837

838

839

840

841

842

843

844

845

846

Ethics approval and consent to participate Not applicable.

Consent for publication Not applicable.

Competing interests The authors declare no competing interests

\section{References}

Abajobir, A., Abbafati, C., Abbas, K.M., Abd-Allah, F., Abera, S.F., et al., 2017. Global,regional, and national age-sex specific mortality for 264 causes of death, 1980-2016:a systematic analysis for the Global Burden of Disease Study 2016. Lancet. 390,1151-1210.

Acemoglu, D., Aghion, P., Bursztyn, L., and Hemous, D., 2012.The environment and directed technical change. Am. Econ. Rev. 102(1), 131-166.

Aghion, P., Dechezleprêtre, A., Hemous, D., Martin, R., and Reenen, J. V., 2016 .Carbon taxes, path dependency, and directed technical change: Evidence from the auto industry. J. Polit. Econ.124(1), 1-51.

Apte, J.S., Marshall, J.D., Cohen, A.J., et al., 2015. Addressing global mortality from ambient PM2.5. Environ. Sci. Technol. 49 (13), 8057-8066.

Arthur, W.B., 1989. Competing technologies, increasing returns, and lock-in by historical events. Econ. J. 394, 116-131.

Asumadu-Sarkodie, S., Adams, S., Leirvik, T., 2020. Foreign direct investment and renewable energy in climate change mitigation: Does governance matter?. J.Clean.Prod. 263,121262.

Baron, R.,Kenny, D.,1986. The moderator-mediator variable distinction in social psychological research: conceptual, strategic, and statistical considerations. J. Pers .Soc. Psychol. 51(6).

Cai, W.,Hui, J.,Wang, C.,et al., 2018.The Lancet countdown on PM2·5pollution-related health impacts of China's projected carbon dioxide mitigation in the electric power generation sector under the Paris Agreement: A modelling study. Lancet Planet. Health 2,151-161.

Cao, C., Cui, X., Cai, W., et al., 2019.Incorporating health co-benefits into regional carbon emission reduction policy making: A case study of China's power sector. Appl. Energy. 253.

Chang, S., Yang, X., Zheng, H., et al., 2020. Air quality and health co-benefits of China's national emission trading system. Appl. Energy, 261,114226.

Chen, S., Zhang, Y., et al., 2019. The relationship between industrial restructuring and China's regional haze pollution: A spatial spillover perspective. J.Clean.Prod. 239.

Chin-Yu, Hsu, Hung-Che, Chiang, Mu-Jean, \& Chen, et al., 2017. Ambient pm2.5 in the residential area near industrial complexes: spatiotemporal variation, source apportionment, and health impact. Sci. Total Environ. 590-591

Coelho, S., Rafael, S., Lopes D., et al.,2020.How changing climate may influence air pollution control strategies for 2030?. Sci. Total Environ.758,143911.

Cunico., et al.,2017. Eco-innovation and technological cooperation in cassava processing companies: structural equation modeling. Revista de Administração, (52),36-46. 
Dietz, T., Rosa, E.A., 1994.Rethinking the environmental impacts of population,affluence, and technology. Hum. Ecol. Rev. 1, 277-300.

Dong, F., Zhang, S., Long, R., et al., 2019. Determinants of haze pollution: An analysis from the perspective of spatiotemporal heterogeneity. J.Clean.Prod. 222(JUN.10), 768-783.

Dong, H., Dai, H., Dong, L., et al., 2015. Pursuing air pollutant co-benefits of CO2 mitigation in China: a provincial leveled analysis. Appl. Energy. 144(15), 165-174.

Driscoll, C., Buonocore, J., Levy, J., et al., 2015.US power plant carbon standards and clean air and health co-benefits. Nat.Clim. Chang. 5,535-540.

Du, K., Cheng, Y., Yao, X., 2021. Environmental regulation, green technology innovation, and industrial structure upgrading: The road to the green transformation of Chinese cities. Energy Econ.98.

Ehrlich, P.R., Holdren, J.P., 1971. Impact of population growth. Science 171,1212-1217.

Fan, X., Xu, Y., 2020. Convergence on the haze pollution: City-level evidence from China. Atmospheric Pollut. Res. 11(6).

Feng, Z., Robert, C. 2012. Toward an environmentally sustainable future: country environmental analysis of the people's republic of China. Asian Development Bank: Mandaluyong City, Philippines.

Feng. Y.,Wang, X.,Liang, Zhou., 2021. How does environmental information disclosure affect economic development and haze pollution in Chinese cities? The mediating role of green technology innovation. Sci. Total Environ. 775.

Gan, T., Liang, W., Yang, H., Liao, X., 2020. The effect of Economic Development on haze pollution (PM 2.5 ) based on a spatial perspective: Urbanization as a mediating variable. J.Clean.Prod. 266.

Garcia-Menendez, F., Saari, R., Monier, E., Selin, N.,2015. US air quality and health benefits from avoided climate change under greenhouse gas mitigation. Environ Sci \&Technol , 49, 7580-8.

Grossman, G., Krueger, A., 1992. Environmental Impacts of a North American Free Trade Agreement. CEPR Discussion Papers, 8(2),223-250.

Guan, D. , Zhu, L. , Yong, G. , Lindner, S. , \& Hubacek, K.,2012.The gigatonne gap in china's carbon dioxide inventories. Nat.Clim. Chang.

Guan, W.J., Zheng, X.Y., Chung, K.F., Zhong, N.S., 2016. Impact of air pollution on the burden of chronic respiratory diseases in China: time for urgent action. Lancet 388,1939-1951.

Guan, Y., Kang, L., Wang Y., et al.,2019. Health loss attributed to PM_(2.5) pollution in China's cities: Economic impact, annual change and reduction potential. J.Clean.Prod.217(APR.20):284-294.

Han, X., Liu, Y., Gao, H., Ma, J., Mao, X., Wang, Y., Ma, X., 2017. Forecasting PM 2.5induced male lung cancer morbidity in China using satellite retrieved PM 2.5 and spatial analysis. Sci. Total Environ. 607, 1009-1017.

Hao, Y., \& Liu, Y.M.,2016. The influential factors of urban pm2.5 concentrations in china: a spatial econometric analysis.J.Clean.Prod.112(JAN.20PT.2), 1443-1453.

Hao, Y., Zhang, Z., Liao, H., et al., 2015. China's farewell to coal: A forecast of coal consumption through 2020. Energy Policy, 86(NOV.),444-455.

He, K., Lei, Y., Pan, X., et al., 2010. Co-benefits from energy policies in China. Energy.35(11), 4265-4272.

Horbach, J., Rammer, C., Rennings, K., 2012. Determinants of eco-innovations by type of 
environmental impact-the role of regulatory push/pull, technology push and market pull. Ecol. Econ. 78 (6), 112-122.

Jing, C.,Zhou, C.,Wang, S. et al., 2018. Impacts of energy consumption structure, energy intensity, economic growth, urbanization on PM 2.5 concentrations in countries globally. Appl. Energy. 230,94-105.

Jintai, Lin, Chris, P., Nielsen, \& Yu, et al. (2010). Recent changes in particulate air pollution over china observed from space and the ground: effectiveness of emission control. Environ. Sci. Technol. 44(20), 7771-7776.

Kamal Jyoti Maji,Ye W.,Mohit Arora,S.M. Shiva Nagendra., 2018. PM 2.5 -related health and economic loss assessment for 338 Chinese cities. Environ.Int. 121.

Kanada, M., Liang, D., Fujita, T., et al., 2013. Regional disparity and cost-effective SO2 pollution control in China: A case study in 5 mega-cities. Energy Policy. 61(oct.),1322-1331.

Kearsley, A., Riddel, M. 2010. A further inquiry into the Pollution Haven Hypothesis and the Environmental Kuznets Curve. Ecol. Econ. 69, 905-919.

Khan, A., Yang, C., Hussain, J., et al., 2021. Impact of technological innovation, financial development and foreign direct investment on renewable energy, non-renewable energy and the environment in belt \& Road Initiative countries. Renew. Energ. 171,479-491.

Kuznets, S., 1955. Economic growth and income inequality. Am. Econ. Rev. 45, 1-28.

Landrigan, P, J,et al.,2018.The Lancet Commission on pollution and health. The Lancet,391(10119).

Lanzi, E.,Dellink, R.,Chateau, J.,2018.The sectoral and regional economic consequences of outdoor air pollution to 2060.Energy Econ. 71(MAR.),89-113.

Li, F., Xu, X., Li, Z., et al., 2021. Can low-carbon technological innovation truly improve enterprise performance? The case of Chinese manufacturing companies. J.Clean.Prod. 293,125-949.

Li, G., Wang, X., Su, S., et al., 2019. How green technological innovation ability influences enterprise competitiveness. Technol. Soc. 59,101-136.

Li, H., You, S.,Zhang H, Zheng WD, Zheng XJ, Jia J, et al., 2017. Modelling of AQI related to building space heating energy demand based on big data analytics. Appl. Energy. 203,57-71.

Li, M., Zhang, D., Li, C., Kathleen, M., Mulvaney, Noelle, E.Selin,Valerie J. Karplus., 2018. Author Correction: Air quality co-benefits of carbon pricing in China. Nat.Clim. Chang. 8(8).

Li, T., Horton, R.M., Bader, D.A., Liu, F., Sun, Q., Kinney, P.L., 2018. Long-term projections of temperature-related mortality risks for ischemic stroke, hemorrhagic stroke, and acute ischemic heart disease under changing climate in Beijing, China. Environ.Int. 112, 1-9.

Li, Z., Sun, L., Geng, Y., et al., 2017. Examining industrial structure changes and corresponding carbon emission reduction effect by combining input-output analysis and social network analysis: A comparison study of China and Japan. J.Clean.Prod.162:61-70

Liao, T., Wang, S., Ai, J., Gui, K., Duan, B., \& Zhao, Q., et al., 2017. Heavy pollution episodes, transport pathways and potential sources of pm2.5 during the winter of 2013 in chengdu (china). Sci. Total Environ. 584-585(apr.15), 1056-1065.

Lin, B., Zhu, J., 2019. The role of renewable energy technological innovation on climate change: Empirical evidence from China. Sci. Total Environ. 659,1505-1512.

Lin, B.,Chen, X., 2020. How technological progress affects input substitution and energy efficiency in China: A case of the non-ferrous metals industry. Energy, 206. 
Lin, B.,Chen, Y., 2019. Impacts of policies on innovation in wind power technologies in China.Appl. Energy. 247(AUG.1),682-691.

Lin, C.Q., Liu, G., Lau, A.K.H., Li, Y., Li, C.C., Fung, J.C.H., Lao, X.Q., 2018. High-resolution satellite remote sensing of provincial PM2.5 trends in China from 2001 to 2015. Atmos. Environ. 180, 110-116.

Liu, S., Xing, J., Westervelt, D., et al.,2020. Role of emission controls in reducing the 2050 climate change penalty for PM2.5 in China. Sci. Total Environ. 765(6), 144338.

Liu, T., Cai, Y., Feng, B., Cao, G., Lin, H., Xiao, J., Li, X., Liu, S., Pei, L., Fu, L., Yang, X.,Zhang, B., Ma, W., 2018. Long-term mortality benefits of air quality improvement during the twelfth five-year-plan period in 31 provincial capital cities of China.Atmos. Environ. 173, 53-61.

Liu, Y.Q., Zhao, G.H., Zhao, Y.S., 2016. An analysis of Chinese provincial carbon dioxide emission efficiencies based on energy consumption structure. Energy Policy 96,524-533

Luo, Y., Salman, M., Lu, Z., 2021. Heterogeneous impacts of environmental regulations and foreign direct investment on green innovation across different regions in China. Sci. Total Environ. 759.

Lyu, W., Li, Y., Guan, D.B., Zhao, H.Y., Zhang, Q., Liu, Z., 2016. Driving forces of Chinese primary air pollution emissions: an index decomposition analysis.J. Clean.Prod. 133, 136-144.

Mao, X., Xing, Y., Hu, T., et al., 2012.An environmental-economic analysis of carbon, sulfur and nitrogen co-reduction path for China's power industry. China Environmental Science, 32(4),748-756.

Ministry of Ecology and Environment, P. R. of C, 2020. 2019 Report on the State of the Ecology and Environment in China. Beijing. Retrieved from.http://english.mee.gov.cn/Resources/Reports/soe/SOEE2019/202012/P02020121558745 3898053.pdf

Nemet, G. F., Holloway, T. \& Meier, P., 2010.Implications of incorporating air-quality co-benefits into climate change policymaking. Environ. Res. Lett. 5, 014007.

Nielsen, C., Ho, M,. Clearer skies over China :[M]// Clearer Skies Over China. The MIT Press, 2013.

Oosterhaven, J., Broersma, L., 2007. Sector structure and cluster economies: a decomposition of regional labour productivity. Reg. Stud. 41 (5), 639-659.

Opoku, E.,Adams, S., Aluko, O., 2021. The foreign direct investment-environment nexus: Does emission disaggregation matter?. Energy Rep. 7.

Ou, Y., Shi, W., Smith, S., et al., 2018. Estimating environmental co-benefits of U.S. low-carbon pathways using an integrated assessment model with state-level resolution. Appl. Energy, 216,482-493.

Ou, Y., Zhai, H., Rubin, E.,2016. Life cycle water use of coal- and natural-gas-fired power plants with and without carbon capture and storage. Int J Greenhouse Gas Control, 44,249-61.

Pancera, M., 2013. Innovation system for sustainability in developing countries: The renewable energy sector in Bolivia. Int. J. Innov. Sust. Dev. 7(1),27-45.

Ren et al., 2018. The effects of three types of environmental regulation on eco-efficiency: A cross-region analysis in China. J.Clean.Prod. 173,245-255.

Rypdal, K., Rive, N., Åström, S., et al., 2007. Nordic air quality co-benefits from European post-2012 climate policies. Energy Policy,35(12), 6309-6322. 
Scovronick, N., Budolfson, M., Dennig, F., Errickson, F.,Fleurbaey, M.,Peng,W., Socolow, R.,Spears, D.,Wagner, F., 2019.The impact of human health co-benefits on evaluations of global climate policy. Nat. Commun. 10(1).

Shao, S., Yang, L., Yu, M., et al., 2011. Estimation, characteristics, and determinants of energy-related industrial CO2 emissions in Shanghai (China), 1994-2009. Energy Policy, 39,6476-6494.

Shao, S., Zhang, K., Dou, J.M., 2019. Effects of economic agglomeration on energy saving and emission reduction: theory and empirical evidence from China. Manag. World.35, 36-60.

Sharifi A.,2020.Co-benefits and synergies between urban climate change mitigation and adaptation measures:A literature review. Sci. Total Environ. 750,141642.

Shen, J., Wang, S., Liu, W., et al., 2019. Does migration of pollution-intensive industries impact environmental efficiency? Evidence supporting "Pollution Haven Hypothesis".J. Environ. Manage. 242(JUL.15),142-152.

Shindell, D., Faluvegi, G., Seltzer, K., et al., 2018. Quantified, localized health benefits of accelerated carbon dioxide emissions reductions. Nat.Clim. Chang. (In press)

Shindell, D., Lee, Y., Faluvegi, G., 2016. Climate and health impacts of US emissions reductions consistent with $2^{\circ} \mathrm{C}$. Nat.Clim. Chang. 6, 503507.

Sobel, M., 1988. Direct and indirect effects in linear structural equation models. In:Long, J.S. (Ed.), Common Problems/proper Solutions. Sage, Beverly Hills, CA,pp. 46-64.

Thompson, T., Rausch, S., Saari, R., et al., 2014 A systems approach to evaluating the air quality co-benefits of US carbon policies. Nat.Clim. Chang. 4(10),917-923.

Tollefsen, P., Rypdal, K., Torvanger, A., et al., 2009. Air pollution policies in Europe: Efficiency gains from integrating climate effects with damage costs to health and crop s. Environ. Sci. Technol. 12(7),870-881.

Tong, S., Ebi, K., 2019.Preventing and mitigating health risks of climate change. Environ. Res. 174.

Trail, M., Tsimpidi, A., Liu, P., Tsigaridis, K., Hu, Y., Rudokas, J., et al.,2015. Impacts of potential $\mathrm{CO} 2$ reduction policies on air quality in the United States. Environ. Sci\&Technol , 49, 513341.

Tursun, H., et al., 2015. Contribution weight of engineering technology on pollutant Emission reduction based on IPAT and LMDI methods. Clean Technol. Environ.Policy 17 (1), 225235.

Wang, H., Wang, M., 2020. Effects of technological innovation on energy efficiency in China: Evidence from dynamic panel of 284 cities. Sci. Total Environ. 709.

Wang, T., Jiang, Z., Zhao, B., et al., 2020. Health co-benefits of achieving sustainable net-zero greenhouse gas emissions in California. Nat. Sustain. (In press)

Wang, W., Li Y., Lu N., Wang., D., \& Zhang, C., 2019. Does increasing carbon emissions lead to accelerated eco-innovation? empirical evidence from china. J.Clean.Prod. 251, 119690.

Wang, W., Wang, D., Ni, W., et al., 2020. The impact of carbon emissions trading on the directed technical change in China. J.Clean.Prod. 272, 122891.

Wang, Z., Fang, C., 2016. Spatial-temporal characteristics and determinants of PM 2.5 in the Bohai Rim Urban Agglomeration. Chemosphere, 148.

West, J., Osnaya, P., Laguna, I., et al., 2004. Co-control of urban air pollutants and greenhouse gases in Mexico City. Environ. Sci. Technol. 38(13), 3474-3481. 
West, J., Smith, S., Silva, R., et al., 2013. Co-benefits of mitigating global greenhouse gas emissions for future air quality and human health. Nat.Clim. Chang. 3,885-9.

Wright, C.Y., et al.,2021. Major climate change-induced risks to human health in South Africa. Environ. Res. 196, p. 110973.

Wurlod., Jules-Daniel, Noailly, et al., 2018. The impact of green innovation on energy intensity: An empirical analysis for 14 industrial sectors in OECD countries. Energy Econ. 71.

Xie, Y., Dai, H., Xu, X., et al.,2018. Co-benefits of climate mitigation on air quality and human health in Asian countries. Environ.Int. 119(OCT.),309-318.

Xie, Y., Dai, H., Zhang, Y., Wu, Y., \& Toshihiko, M.,2019. Comparison of health and economic impacts of pm2.5 and ozone pollution in china.Environ.Int. 130, 104881.

Xu, B., Luo, L., Lin, B., 2016. A dynamic analysis of air pollution emissions in China:Evidence from nonparametric additive regression models. Ecol. Indic. 63,346-358.

Yang, D., Chen, Y., Miao, C., Liu, D., 2020. Spatiotemporal variation of PM2.5 concentrations and its relationship to urbanization in the Yangtze river delta region,China. Atmos. Pollut. Res. 11, 491-498.

Yang, J., Li, X., Peng, W., et al., 2018. Climate, air quality and human health benefits of various solar photovoltaic deployment scenarios in China in 2030. Environ.Res.Lett. 13(6).

Yang, J., Zhao, Y., Cao, J., et al., 2021. Co-benefits of carbon and pollution control policies on air quality and health till 2030 in China. Environ.Int. 152,683-693.

Yang, X., Teng, F., Wang, G., 2013. Incorporating environmental co-benefits into climate policies: A regional study of the cement industry in China. Applied Energy, 112: 1446-53.

Yao, X., Kou, D., Shao, S., et al., 2018. Can urbanization process and carbon emission abatement be harmonious? New evidence from China. Environ. Impact Assess. Rev., 71,70-83.

Yeora, C., 2010. Co-benefit analysis of an air quality management plan and greenhouse gas reduction strategies in the Seoul metropolitan area. Environ. Sci. Technol. 13(3), 205-216.

Yin, Z. , \& Zhang, Y., 2020. Climate anomalies contributed to the rebound of pm2.5 in winter 2018 under intensified regional air pollution preventions. Sci. Total Environ. 726, 138514.

Yin, Z., Li, Y., Wang, H., 2019. Response of early winter haze days in the North China plain to autumn Beaufort Sea ice. Atmos. Chem. Phys. 19, 1439-1453.

Yin, Z., Wang, H., 2017. Role of atmospheric circulations in haze pollution in December 2016. Atmos. Chem. Phys. 17, 11673-11681.

Zeng, Y.,Cao Y.,Qiao X.,Barnabas C. Seyler,Tang Y., 2019. Air pollution reduction in China: Recent success but great challenge for the future. Sci. Total Environ.663.

Zhang, J., Chen, Q., Wang, Q, et al.,2019.The acute health effects of ozone and PM_(2.5) on daily cardiovascular disease mortality: A multi-center time series study in China. Ecotox. Environ. Safe. 174(JUN.),218-223.

Zhang, M.,Sun, X.,Wang, W., 2020. Study on the effect of environmental regulations and industrial structure on haze pollution in China from the dual perspective of independence and linkage. J.Clean.Prod. 256,120-748.

Zhang, N.,Wu, Y., Yongrok, C., 2020. Is it feasible for China to enhance its air quality in terms of the efficiency and the regulatory cost of air pollution?. Sci. Total Environ. 709.

Zhang, S.L., Li, Y., Hao, Y., Zhang, Y.P., 2018. Does public opinion affect air quality? Evidence based on the monthly data of 109 prefecture-level cities in China. Energy Policy 116, 299311. 
Zhang, Y., Smith, S., Bowden J., et al., 2017. Co-benefits of global, domestic, and sectoral greenhouse gas mitigation for US air quality and human health in 2050. Environ. Res. Lett. 12(11), 114033.

Zhao, D., Chen, H., Li, X., et al., 2018.Air pollution and its influential factors in China's hot spots. Journal of Cleaner Production,619-627.

Zhao, H., Chen, K., Liu, Z., Zhang, Y., \& Zhang, H., 2020. Coordinated control of pm2.5 and o3 is urgently needed in china after implementation of the "air pollution prevention and control action plan". Chemosphere, 270.

Zhao, J., Jiang, Q., Dong, X., et al., 2020. Would environmental regulation improve the greenhouse gas benefits of natural gas use? A Chinese case study. Energy Econ. 87.

Zhao, M., Sun, T., Feng Q., 2021. Capital allocation efficiency, technological innovation and vehicle carbon emissions: Evidence from a panel threshold model of Chinese new energy vehicles enterprises. Sci. Total Environ. 784.

Zhao, X., Sun, B., 2015. The influence of Chinese environmental regulation on corporation innovation and competitiveness. J. Clean. Prod. 1 12, 1528-1536

Zhao, X., Wang, W., 2020. Driving force for China's photovoltaic industry output growth: Factor-driven or technological innovation-driven?. J.Clean.Prod. 274,122848.

Zheng, J., Shao, X., Liu, W., et al., 2021. The Impact of the Pilot Program on Industrial Structure Upgrading in Low-carbon Cities. J.Clean.Prod. 290(1),125-868.

Zhou, C., Chen, J., Wang S., 2018. Examining the effects of socioeconomic development on fine particulate matter (PM2.5) in China's cities using spatial regression and the geographical detector technique.Sci. Total Environ. 619-620,436-45.

Zhou, Q., et al., 2021. Environmental regulation and haze pollution: Neighbor-companion or neighbor-beggar? Energy Policy. 151, 112-183.

Zhu, L., Hao, Y., Lu, Z., et al., 2019. Do economic activities cause air pollution? Evidence from China's major cities. Sustain. Cities Soc. 49,101593. 